\title{
Ice-Atmosphere Feedbacks Dominate the Response of the Climate System to Drake Passage Closure $\mathfrak{\emptyset}$
}

\author{
Matthew H. England, David K. Hutchinson, ${ }^{a}$ Agus Santoso, And Willem P. Sijp \\ ARC Centre of Excellence for Climate System Science, University of New South Wales, Sydney, \\ New South Wales, Australia
}

(Manuscript received 30 July 2015, in final form 30 March 2017)

\begin{abstract}
The response of the global climate system to Drake Passage (DP) closure is examined using a fully coupled ocean-atmosphere-ice model. Unlike most previous studies, a full three-dimensional atmospheric general circulation model is included with a complete hydrological cycle and a freely evolving wind field, as well as a coupled dynamic-thermodynamic sea ice module. Upon DP closure the initial response is found to be consistent with previous ocean-only and intermediate-complexity climate model studies, with an expansion and invigoration of the Antarctic meridional overturning, along with a slowdown in North Atlantic Deep Water (NADW) production. This results in a dominance of Southern Ocean poleward geostrophic flow and Antarctic sinking when DP is closed. However, within just a decade of DP closure, the increased southward heat transport has melted back a substantial fraction of Antarctic sea ice. At the same time the polar oceans warm by $4^{\circ}-6^{\circ} \mathrm{C}$ on the zonal mean, and the maximum strength of the Southern Hemisphere westerlies weakens by $\simeq 10 \%$. These effects, not captured in models without ice and atmosphere feedbacks, combine to force Antarctic Bottom Water (AABW) to warm and freshen, to the point that this water mass becomes less dense than NADW. This leads to a marked contraction of the Antarctic overturning, allowing NADW to ventilate the abyssal ocean once more. Poleward heat transport settles back to very similar values as seen in the unperturbed DP open case. Yet remarkably, the equilibrium climate in the closed DP configuration retains a strong Southern Hemisphere warming, similar to past studies with no dynamic atmosphere. However, here it is ocean-atmosphere-ice feedbacks, primarily the ice-albedo feedback and partly the weakened midlatitude jet, not a vigorous southern sinking, which maintain the warm polar oceans. This demonstrates that DP closure can drive a hemisphere-scale warming with polar amplification, without the presence of any vigorous Southern Hemisphere overturning circulation. Indeed, DP closure leads to warming that is sufficient over the West Antarctic Ice Sheet region to inhibit ice-sheet growth. This highlights the importance of the DP gap, Antarctic sea ice, and the associated icealbedo feedback in maintaining the present-day glacial state over Antarctica.
\end{abstract}

\section{Introduction}

The landmass geometry around Antarctica has varied substantially over the past 100 million years, with a Southern Ocean gateway only established about 30 million years ago (Barker and Burrell 1977; Stickley et al. 2004) once both modern-day Australia and South

Supplemental information related to this paper is available at the Journals Online website: http://dx.doi.org/10.1175/ JCLI-D-15-0554.s1.

${ }^{\text {a }}$ Current affiliation: Bolin Centre for Climate Research, and Department of Geological Sciences, Stockholm University, Stockholm, Sweden.

Corresponding author: Matthew H. England, m.england@ unsw.edu.au
America broke away from Antarctica. It is still debated to what extent the establishment of a circumpolar Southern Ocean influences global climate. While model (Toggweiler and Bjornsson 2000; Sijp et al. 2009, and references therein) and paleoclimate (e.g., Kennett 1977) evidence suggests that the opening of a Southern Ocean gateway could have contributed to the glaciation of Antarctica, other work argues for a weaker effect (e.g., Livermore et al. 2005; Huber and Nof 2006; Huber and Sloan 2001). Fundamental ocean physics dictates that when the Southern Ocean gateway is open, no net meridional geostrophic flow can cross the Drake Passage (DP) gap (Toggweiler and Samuels 1995). This constraint can yield significant differences in the ocean thermohaline circulation in model experiments wherein the same basic configuration is run with, and without, a Drake Passage gap. An open gap also enables the 
establishment of an Antarctic Circumpolar Current (ACC), which can lead to thermal isolation of Antarctica. Most studies have hitherto focused on the meridional overturning circulation (MOC) and ACC response to changes in a Southern Ocean gateway. Here we will show how important ice-albedo feedbacks can dominate the climate response to the establishment of a Southern Ocean gateway.

The pioneering paper of Gill and Bryan (1971) was the first to demonstrate the fundamental role of the DP gap in controlling global ocean circulation. Beyond the obvious nonexistence of a circumpolar current, Gill and Bryan (1971) showed that closure of the DP gap, and therefore the provision of a western boundary, also enables net meridional geostrophic flow across the Southern Ocean, something that is impossible in today's climate with the absence of zonal land boundaries. In Gill and Bryan (1971) the resultant overturning circulation without a DP gap becomes dominated by a vast southern sinking cell, characterized by enhanced poleward heat transport (PHT) to the south, warmed upperocean temperatures around Antarctica, and greatly enhanced production rates of the model equivalent of Antarctic Bottom Water (AABW). While Gill and Bryan (1971) performed their experiments within a simplified Southern Hemisphere sector model, excluding interactions with the Northern Hemisphere, similar results are obtained when global ocean models are used (e.g., Cox 1989; England 1993; Toggweiler and Samuels 1995). These global models further suggest a suppression of North Atlantic Deep Water (NADW) due to the vigor and northward penetration of the strong southern sinking cell when DP is closed.

In addition to the above, several other studies have explored the ocean circulation response to opening and closing the Drake Passage, and most have incorporated either ocean-only models (e.g., England 1993; Toggweiler and Samuels 1995) or ocean models coupled to simplified atmospheric models (e.g., Nong et al. 2000; Najjar et al. 2002; Toggweiler and Bjornsson 2000; Sijp and England 2004; Sijp et al. 2009). In all of these past studies the mechanism invoked to explain the climate response to DP opening is focused on the meridional overturning circulation, and specifically the dominance of a vigorous global-scale Southern Ocean cell when DP is closed, transporting a large amount of heat poleward, versus the present-day configuration of a circumpolar flow that isolates Antarctica, inhibiting meridional geostrophic flow across the DP gap. This difference in the MOC yields a substantially colder Antarctica when the DP is open compared to when DP is closed. Yet these studies employ models wherein either no or only limited atmospheric feedbacks and hydrological cycle are resolved, and so questions remain as to the applicability of these results to the real world. Here we will undertake coupled climate experiments aimed at investigating the role of the Southern Ocean gateway in global climate, in isolation of other factors such as orbital cycles and atmospheric $\mathrm{CO}_{2}$, but importantly including a full dynamic atmosphere coupled to ocean-sea ice and land surface models.

There have been only a few studies of the DP effect undertaken using a coupled climate model. For example, Hutchinson et al. (2013) examine the role of the Drake Passage in generating the well-known interhemispheric warming asymmetry found in response to increasing greenhouse forcing. They attribute part of this asymmetry to the thermal isolation of Antarctica facilitated by the ACC. However, when models are configured using solar, landmass, and $\mathrm{CO}_{2}$ values typical of the Eocene-Oligocene era, the ACC is not necessarily established immediately upon opening a southern gateway (Lefebvre et al. 2012; Hill et al. 2013), and studies suggest that Antarctic cooling foremost requires a decrease in atmospheric $\mathrm{CO}_{2}$ concentrations, not an opening of the DP gateway (e.g., Huber et al. 2004; Goldner et al. 2013, 2014). These two factors- $\mathrm{CO}_{2}$ decreases and an open Southern Ocean gateway-are not, of course, mutually exclusive; indeed the cooling induced by opening the DP could have led to increased ocean carbon uptake via solubility effects. Furthermore, the precise model configuration of the Drake Passage geometry adopted for the Eocene-Oligocene boundary in the Cenozoic can influence the results (e.g., Zhang et al. 2010). A more recent study is that of Yang et al. (2014), which examines the role of the Panama Seaway on the DP effect. They found that imposing an open Panama Seaway in their model, which was inferred prior to 14 million years ago from paleo-proxy records, results in their DP effect being more dramatic. Our focus here, however, is not on a paleoclimatic reconstruction of the events that took place upon gateway opening across the Eocene-Oligocene boundary. As in Hutchinson et al. (2013), our interest is more related to the climate dynamics, feedbacks, and processes that define the role of the DP gap in the modern-day climate system, as this has potential implications for future patterns of global warming. For this reason we do not configure the model for any paleoclimate simulations; instead we adopt a modern-day configuration. While prior studies tend to focus on the equilibrium response, here we also closely examine the transient evolution of key climatic features to provide more insight into the associated dynamics of the DP effect. We will show how an open Southern Ocean gateway facilitates the expanse of sea ice and the associated cold present-day climate around Antarctica. 
Past work exploring the Drake Passage effect in the modern-day climate system has identified both the lack of an ACC and changes in the meridional overturning circulation as key drivers of Antarctic warming when DP is closed. In this study, employing a full-coupled climate model, we will show that despite an initial invigoration of a global-scale Southern Ocean cell when DP is closed, with AABW production reaching almost $50 \mathrm{~Sv}\left(1 \mathrm{~Sv} \equiv 10^{6} \mathrm{~m}^{3} \mathrm{~s}^{-1}\right)$, this rapidly decays back to typical modern-day (DP open) values. In fact our two model simulations in coupled mode, one with and one without a DP gap, yield remarkably similar poleward heat transport fields at most southern latitudes. Yet the climate response when DP is closed is characterized by a much warmer SH climate; this turns out to be largely the result of an ice-albedo amplifying feedback wherein reduced Antarctic sea ice enables a warmer upper ocean, which inhibits ice regrowth. We further show that a DP closed geometry leads to a modest reduction in the subpolar westerly winds over the Southern Ocean, further enabling a warm polar ocean to persist despite minimal change in the Antarctic meridional overturning circulation.

\section{Climate model and experimental design}

This study employs the Commonwealth Scientific and Industrial Research Organisation Mark 3L (CSIRO Mk3L) coupled climate model, comprising fully interactive ocean, atmosphere, land surface, and sea ice submodels (Phipps et al. 2011, 2013). The version used here is that of Santoso et al. (2012), which includes an improved representation of the geometry in the Indonesian Seaway. The model was designed specifically for millennial-scale climate simulations and has been shown to simulate various aspects of the climate system with a good degree of fidelity (e.g., Santoso et al. 2011, 2012; Hutchinson et al. 2013). Of particular relevance to this study is the model's ability to capture a correct representation of Antarctic sea ice coverage, extent, and seasonality. In this regard, average maximum September sea ice extent in the model $\left(18.0 \times 10^{6} \mathrm{~km}^{2}\right)$ fits well within the observed range during 1979-2006 (from $17.5 \times 10^{6}$ to $18.9 \times 10^{6} \mathrm{~km}^{2}$; Cavalieri and Parkinson 2008). Furthermore, in both the model and observations, very little of this sea ice is multiyear, with only on average $3.0 \times 10^{6} \mathrm{~km}^{2}$ remaining during summer, again well within the range from $2.5 \times 10^{6}$ to $3.8 \times 10^{6} \mathrm{~km}^{2}$ found in observations (Cavalieri and Parkinson 2008).

The atmospheric model has $5.6^{\circ}$ longitude $\times 3.2^{\circ}$ latitude resolution, with 18 vertical levels. It resolves full annual and diurnal cycles and includes a cumulus convection scheme based on the Met Office scheme
(Gregory and Rowntree 1990) coupled to the prognostic cloud scheme of Rotstayn (2000). The term cloud cover here is actually referred to generally as cloud amount, which encapsulates both horizontal and vertical components. The atmospheric model implements a prognostic cloud scheme, allowing the model to generate its own physically based cloud properties for any number of cloud layers (Gordon et al. 2002). The atmospheric model is taken from the CSIRO Mk3 model described in Rotstayn (2000) and Gordon et al. (2002); further details of the cloud physics scheme can be found there. The sea ice model includes dynamics and thermodynamics as described in O'Farrell (1998). The land surface model is an enhanced version of the soil-canopy scheme of Kowalczyk et al. (1994) with static vegetation and land surface properties.

The ocean model employed is the GFDL Modular Ocean Model (MOM), based on MOM, version 1.1, but with various enhancements and updates to the physics including implementation of the McDougall et al. (2003) equation of state, updated mixing physics, and other options, as documented in Phipps et al. (2011) and subsequent papers (e.g., Santoso et al. 2011, 2012; Phipps et al. 2013). The ocean model is configured with a horizontal grid resolution of $2.8^{\circ}$ longitude $\times 1.6^{\circ}$ latitude and 21 geopotential levels, increasing in thickness with depth. As detailed in Santoso et al. (2011), diffusivity values are chosen to be within the range of observed estimates (e.g., Cisewski et al. 2005). The vertical diffusivity is set to vary as the inverse of the BruntVäisälä frequency, from a minimum of $3 \times 10^{-5} \mathrm{~m}^{2} \mathrm{~s}^{-1}$ up to enhanced values of between $1.5 \times 10^{-4}$ and $2 \times 10^{-3} \mathrm{~m}^{2} \mathrm{~s}^{-1}$ in the upper $80 \mathrm{~m}$ to incorporate the effect of wind-driven mixing. Whenever static instability arises, vertical diffusivity is increased to $100 \mathrm{~m}^{2} \mathrm{~s}^{-1}$ to simulate the effects of convective mixing. The effects of mesoscale eddies on tracer transport are parameterized using the scheme of Gent and McWilliams (1990, hereafter GM) and Gent et al. (1995). The GM eddy diffusivity varies from $600 \mathrm{~m}^{2} \mathrm{~s}^{-1}$ in the deep ocean, reducing toward zero in the upper layers to satisfy continuity. The model parameters outlined above were found to optimize the realism of the global climate simulation while also minimizing numerical instabilities. Throughout all experiments, the atmospheric $\mathrm{CO}_{2}$ concentration is fixed at the preindustrial level of $280 \mathrm{ppm}$. No flux adjustments have been applied in this study.

While the ocean model resolution for millennial-scale simulations is insufficient to resolve eddies, inclusion of the GM eddy-induced advection scheme approximates the eddy heat transport response when the ACC is established in a Drake Passage open configuration. This occurs in response to the adjustment of isopycnal 
surfaces upon establishment of the ACC, with GM mixing transporting heat poleward via isopycnal layer thickness diffusion. This parameterizes the poleward transport of heat due to eddies in the presence of a midlatitude jet like the ACC. Hence, while eddies are not explicitly resolved by the model, their impact on poleward heat transport is parameterized to capture the richer eddy fluxes present in a DP open configuration compared to when the DP is closed. Ideally the experiments would be run with a state-dependent thickness diffusion coefficient (e.g., Danabasoglu and Marshall 2007). However, to first order, our implementation using a fixed vertical profile for the thickness diffusion coefficient already captures the correct response for the parameterized eddy-advection terms, with weakened eddy-induced advection and poleward heat transport in the absence of an ACC, when the DP is closed. This is discussed further in sections $3 \mathrm{a}$ and $3 \mathrm{c}$.

Two main simulations are investigated in this study. The first experiment uses a standard modern-day landmass configuration $\left(\mathrm{DP}_{\text {open }}\right)$, and the second includes the addition of a land bridge to close the Drake Passage gateway $\left(\mathrm{DP}_{\mathrm{clsd}}\right)$. In all other ways the two experiment configurations are identical-our focus here is thus on the role of a Southern Ocean gateway in the modern-day climate. In terms of model spinup and equilibration, a $\mathrm{DP}_{\text {open }}$ configuration was initially integrated for 1500 years under preindustrial atmospheric $\mathrm{CO}_{2}$ concentrations of $280 \mathrm{ppm}$. Using this equilibrated climate state as the initial conditions, the two different simulations were then integrated a further 2000 years. Thus, both the equilibrated $\mathrm{DP}_{\text {clsd }}$ and $\mathrm{DP}_{\text {open }}$ experiments employ the same initial conditions, with the added benefit that we can track the transient response of the climate system to Drake Passage closure in the $\mathrm{DP}_{\text {clsd }}$ experiment. The equilibrated mean state differences shown in this study (Figs. 7-10, described in greater detail below) are taken from the end of the respective 2000-yr integrations, although it is noted that all fields in the $\mathrm{DP}_{\text {open }}$ experiment are very similar at the end of this 2000-yr integration when compared to the initial conditions. We also evaluated the degree of equilibration of the $\mathrm{DP}_{\text {clsd }}$ experiment at year 2000 by integrating for a further 1000 years to test for ongoing climate adjustments, and only very minor model drift occurred. Most importantly, all results presented are robust to this extended integration time and unchanged at year 3000 relative to year 2000 . Hysteresis behavior was also tested, by reversing the pathway of integration from the equilibrated $\mathrm{DP}_{\text {clsd }}$ experiment forward in time under DP open conditions. No multiple equilibria were obtained, with the model eventually returning to the $\mathrm{DP}_{\text {open }}$ climatic conditions.
In the results presented here, the DP open case will be taken to be the control experiment, with the DP closed climate investigated as a transient response initialized from the open DP case. Previous coupled climate studies examining an open and closed DP configuration have focused on the equilibrated steady-state climates. Here, both the transient response to a closure of the Drake Passage and the final steady-state DP closed climate will be described in relation to their difference from the modern-day DP open geometry. As noted above, the goal of these experiments is not an attempt to reconstruct past paleoclimatic conditions from the Eocene era with closed DP and Tasman Seaways and different greenhouse gas concentrations and orbital parameters. Rather, we aim to examine the processes controlling Southern Hemisphere climate in each configuration, to gain insight into the dynamics regulating Antarctic and Southern Ocean climate in relation to the DP Throughflow.

\section{Results}

\section{a. Meridional overturning circulation}

The meridional overturning circulation in $\mathrm{DP}_{\text {open }}$ and in the transient response to closing DP is summarized in Figs. 1 and 2. A standard preindustrial MOC is simulated in the $\mathrm{DP}_{\text {open }}$ experiment, with $14.8 \mathrm{~Sv}$ of NADW overturning, 5.9Sv of AABW production, and an abyssal cell of strength of $12.3 \mathrm{~Sv}$ (Fig. 1a). Within a year of closing DP, however, a vigorous interhemispheric Southern Ocean overturning cell has been established (Figs. 1b and 2), peaking at $46.1 \mathrm{~Sv}$ and characterized by intense bottom water production and global ventilation of the abyssal oceans from the south. This pattern is typical of that seen in previous model studies using simplified atmospheres and/or ocean-only models to investigate the climate response to DP closure. Within a decade this southern cell has largely suppressed NADW formation, with the Southern Ocean abyssal waters upwelling throughout the world's oceans and the North Atlantic cell contracting to a weakened overturning confined within the Atlantic basin (Fig. 1c). However, even at this stage the southern cell has weakened in amplitude, with the sinking adjacent to Antarctica a small fraction of its peak strength at year 1. By year 50 the Southern Ocean overturning cell has weakened from its peak of $46.1 \mathrm{~Sv}$ down to $10.1 \mathrm{~Sv}$, shoaling to just $1000-\mathrm{m}$ depth, and NADW production has recovered to its $\mathrm{DP}_{\text {open }}$ value of $14.8 \mathrm{~Sv}$, once again exiting into the Southern Ocean (Fig. 1d). From around year 100 until full equilibration, NADW overturning persists at a strength of 9-17 Sv with a mean of $12.5 \mathrm{~Sv}$, eventually ventilating the global oceans at all 
(a) DP Open yr 1500

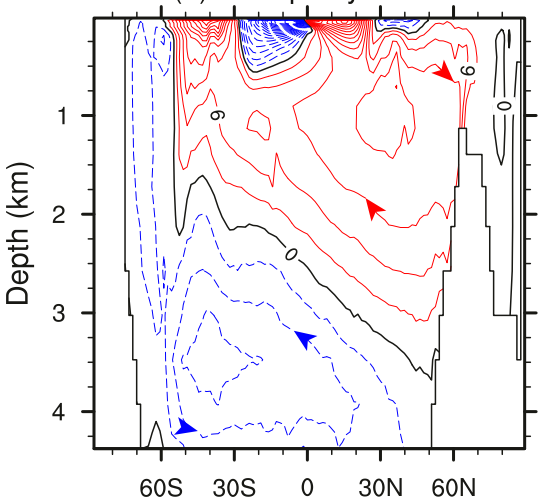

(d) DP Closed yr 10

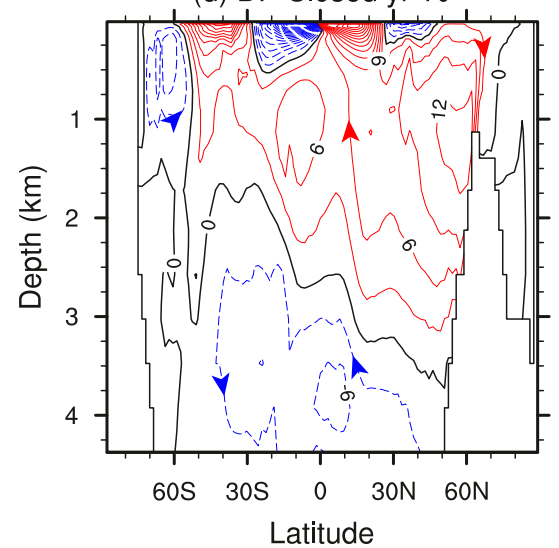

(b) DP Closed yr 1

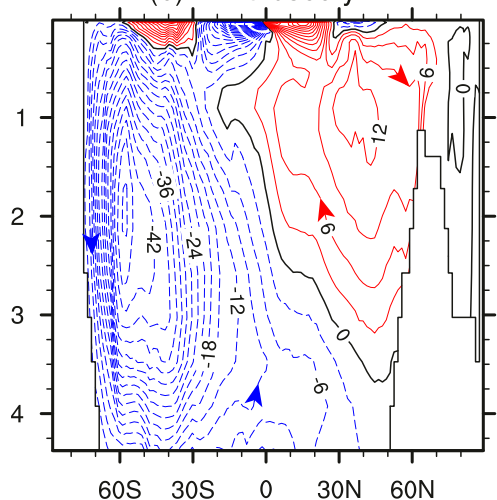

(e) DP Closed yr 100

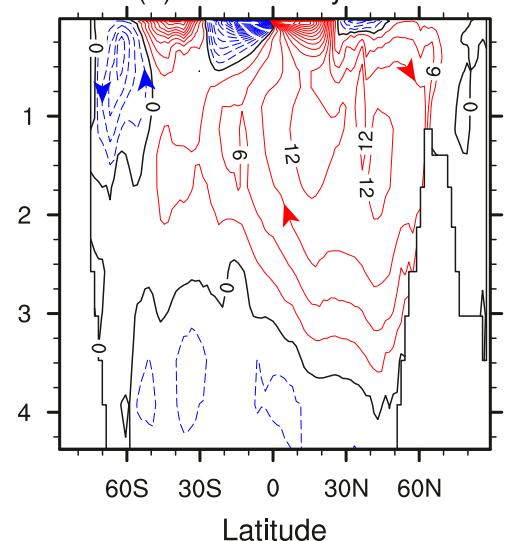

(c) DP Closed yr 5

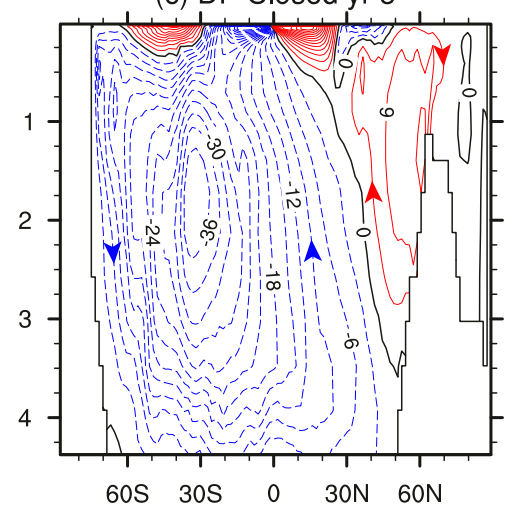

(f) DP Closed yr 2000

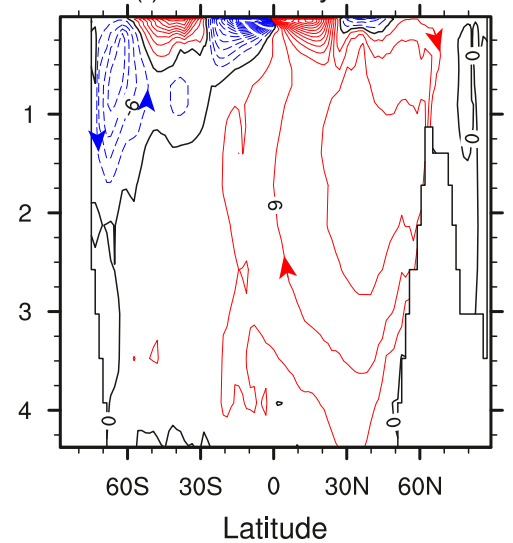

FIG. 1. Global ocean MOC (Sv) in (a) $\mathrm{DP}_{\text {open }}$ and in $\mathrm{DP}_{\text {clsd }}$ during years (b) 1, (c) 5, (d) 10, and (e) 100. Also shown is (f) the equilibrated $\mathrm{DP}_{\text {clsd }} \mathrm{MOC}$ in year 2000. In all plots, MOC is shown as the annual average apart from the equilibrated panels (a) and (f), where a decadelong mean is shown. Contour interval is $3 \mathrm{~Sv}$, red contours denote positive values (clockwise circulation), blue contours denote negative values (anticlockwise circulation), and black is the zero contour.

depths below $1500 \mathrm{~m}$, while the southern cell becomes confined to the upper near-Antarctic region (Fig. 1f). This confined southern cell makes little to no contribution to the abyssal ocean circulation, with water of North Atlantic origin dominating the global abyssal ventilation. Thus, in marked contrast to previous ocean-only and intermediate-complexity climate model (ICCM) studies, no interhemispheric abyssal cell of Southern Ocean origin is captured in the equilibrated $\mathrm{DP}_{\text {clsd }}$ experiment. Instead, the atmosphere-ocean-ice system has adjusted to closing DP in such a way to yield substantially warmer and lighter surface waters around Antarctica.

While the time series of MOC strength reveals that southern Antarctic overturning remains on average higher than NADW production throughout much of the simulation (Fig. 2), the AABW metric is tracking a

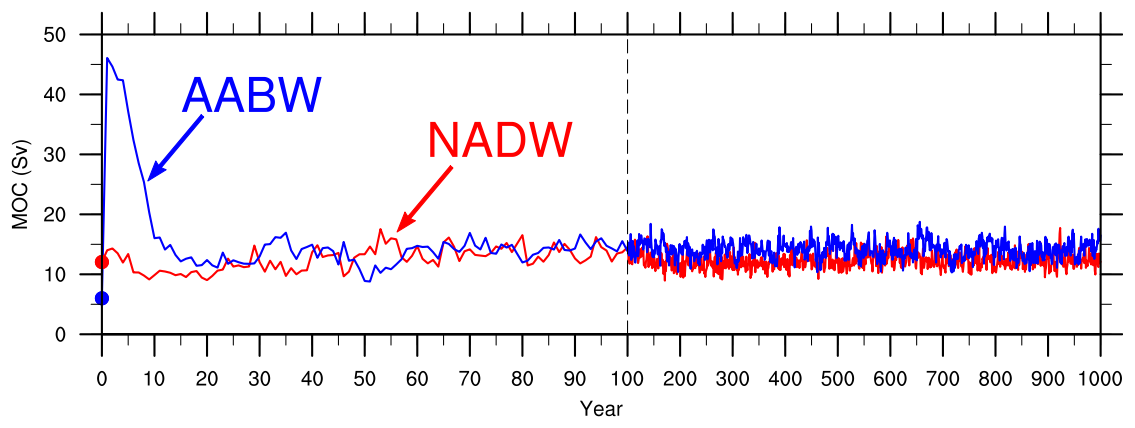

FIG. 2. MOC (Sv) time series of the max overturning rate in the NADW and AABW cells, respectively. Note the two time-axis intervals differ between years 0-100 and years 100-1000. 
(a) DP Open yr 1500

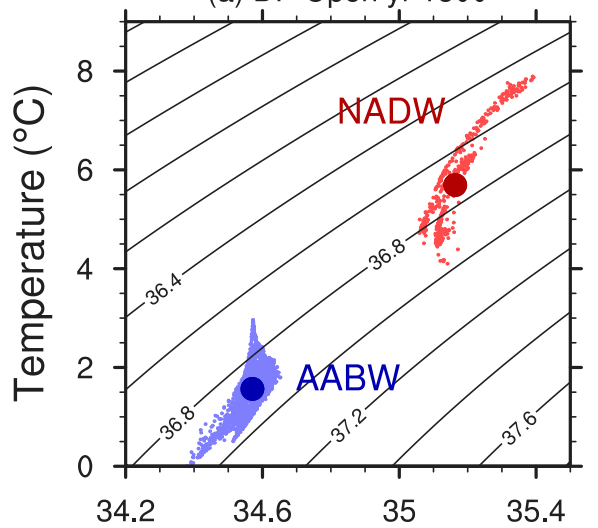

(d) DP Closed yr 50

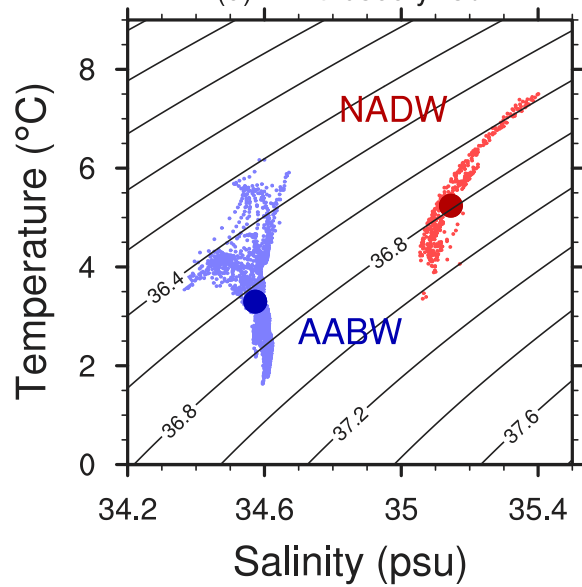

(b) DP Closed yr 1

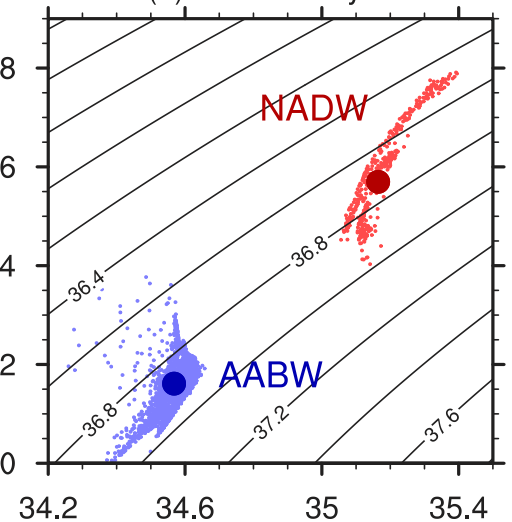

(e) DP Closed yr 100

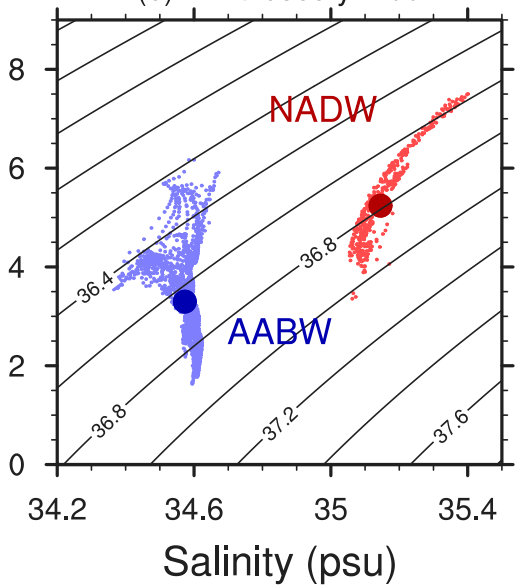

(c) DP Closed yr 10

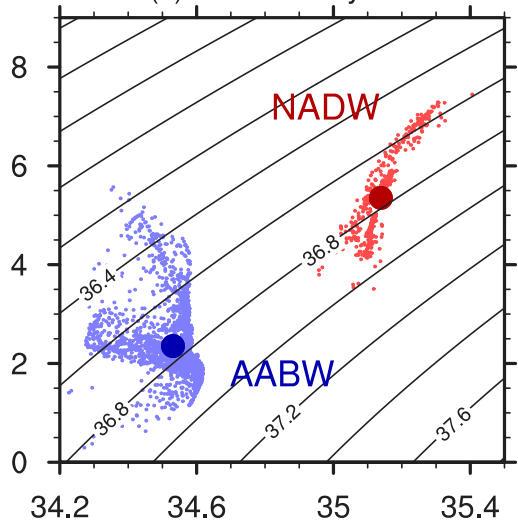

(f) DP Closed yr 2000

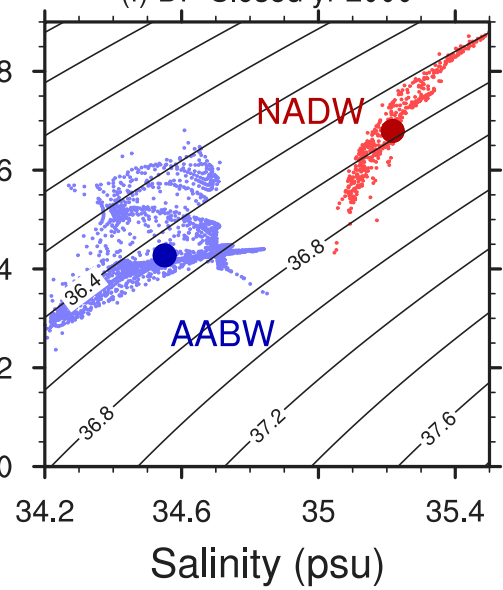

FIG. 3. Volume-weighted average and scatterplot of individual interior $T-S$ values for the NADW and AABW regions for (a) year 1500 in $\mathrm{DP}_{\text {open }}$ and in $\mathrm{DP}_{\text {clsd }}$ during years (b) 1 , (c) 10 , (d) 50 , (e) 100 , and (f) 2000 . The $\mathrm{DP}_{\text {clsd }} T-S$ values are in equilibrium by year 2000 . The $T-S$ values are shown for the respective source water regions at 1000-2000-m depth in the Antarctic south of $60^{\circ} \mathrm{S}$ (blue) and in the North Atlantic between $45^{\circ}$ and $60^{\circ} \mathrm{N}$ (red). Individual values are shown as small dots and the volume-weighted mean as large dots. Overlaid are contours of constant density $\sigma_{2}$ referenced to $2000-\mathrm{m}$ depth $\left(\mathrm{kg} \mathrm{m}^{-3}\right)$.

shallow confined cell that no longer reaches the abyssal oceans by the time of equilibration (Fig. 1f). In contrast NADW ventilates the deep and abyssal layers in the equilibrated $\mathrm{DP}_{\text {clsd }}$ experiment. This is again in marked contrast to previous ocean-only and ICCM studies.

While Fig. 1 reveals the response of the total (i.e., mean plus GM eddy induced) meridional overturning circulation to DP closure, it is of interest to examine the changes in the parameterized eddy-induced MOC separately. These changes occur in response to adjustments in the interior ocean density field (i.e., baroclinicity). Figure S1 in the supplemental material reveals that the eddy-induced advection terms are larger in $\mathrm{DP}_{\text {open }}$ than in $\mathrm{DP}_{\text {clsd }}$, particularly at depth. This adds confidence that the GM scheme is responding appropriately to the gateway changes, as the eddy activity should be damped without an $\mathrm{ACC}$ in $\mathrm{DP}_{\text {clsd }}$, owing to reduced baroclinic instability. In contrast in $\mathrm{DP}_{\text {open }}$, in the presence of an ACC, the density surfaces slope much more steeply in the Southern Ocean, generating larger eddy-induced advection terms. Thus, to first order, the model is responding appropriately when DP is closed, with weakened eddy-induced advection in the absence of an ACC.

\section{b. Deep water masses}

To investigate the MOC response further, an analysis of the transient response in high-latitude water mass properties is summarized in Figs. 3 and 4. Figure 3 shows the evolution of volume-weighted average temperaturesalinity (i.e., $T-S$ ) values in Antarctic and North Atlantic waters in the regions of deep and bottom water mass formation, sampled at the 1000-2000-m depth range to directly evaluate the interhemispheric difference in deep water properties. Figure 4 shows latitude-depth zonal-mean sections of temperature, salinity, and potential density differences between the two experiments $\left(\mathrm{DP}_{\text {clsd }}-\mathrm{DP}_{\text {open }}\right)$ at years 10,100 , and 2000. Initially, with DP open, Antarctic deep waters are much colder, 

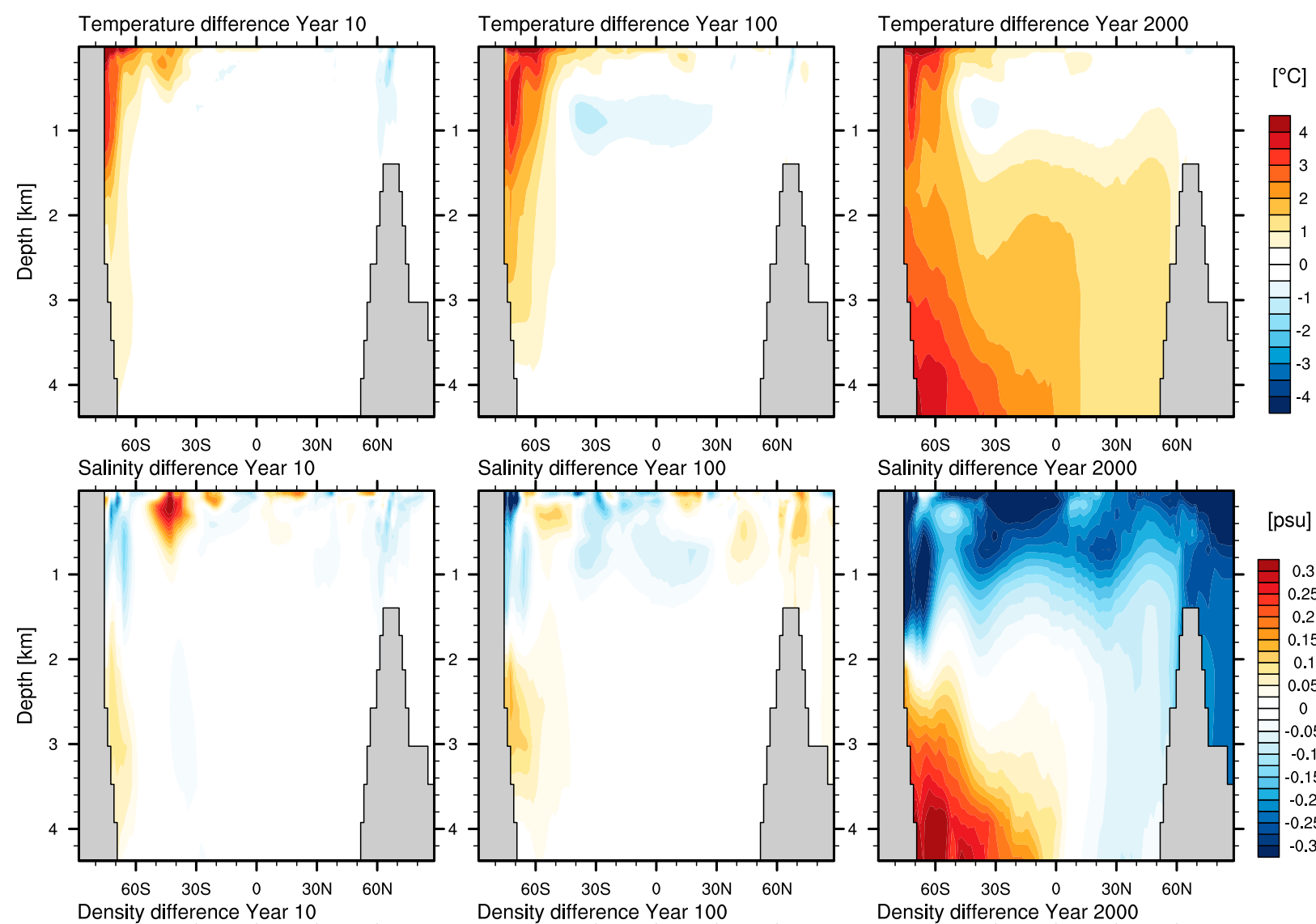

Salinity difference Year 2000
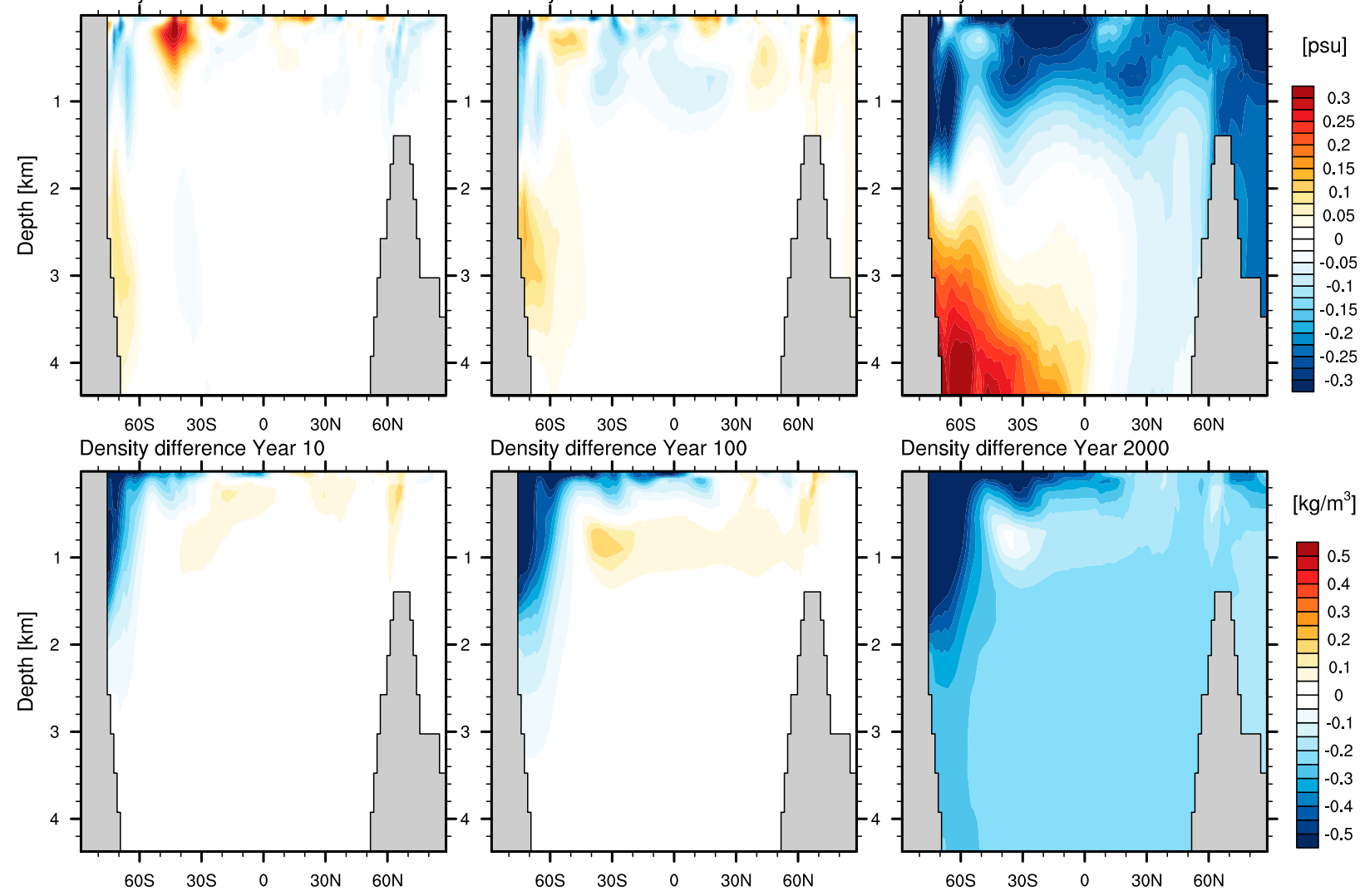

FIG. 4. Latitude-depth global zonal-mean differences in temperature, salinity, and potential density between the two experiments

$\left(\mathrm{DP}_{\text {clsd }}-\mathrm{DP}_{\text {open }}\right)$ during years 10, 100, and 2000.

fresher, and denser than their North Atlantic counterparts (Fig. 3a). The higher density of Antarctic surface waters when DP is initially closed is the reason that a vigorous full-depth overturning cell develops in the south, dominating the global ocean circulation (Figs. 1b, c). This can occur in $\mathrm{DP}_{\text {clsd }}$ (and not $\mathrm{DP}_{\text {open }}$ ) because the land bridge across the DP gap allows meridional geostrophic flow to traverse the Southern Ocean poleward. Once DP is closed, however, the Antarctic surface waters begin to warm and to a lesser extent freshen (Fig. 4, left) in response to increased poleward heat transport and ice melt, gradually becoming less dense as the model integration proceeds (Figs. 3 and 4). Eventually, the Antarctic upper and deep waters become less dense than the corresponding waters in the North Atlantic, triggering a contraction in the vigorous Southern Ocean meridional cell. Yet despite the contraction in this cell, and the abatement in the poleward heat transport anomalies first seen when DP is closed, Antarctic surface waters remain substantially warmer in $\mathrm{DP}_{\text {clsd }}$ 

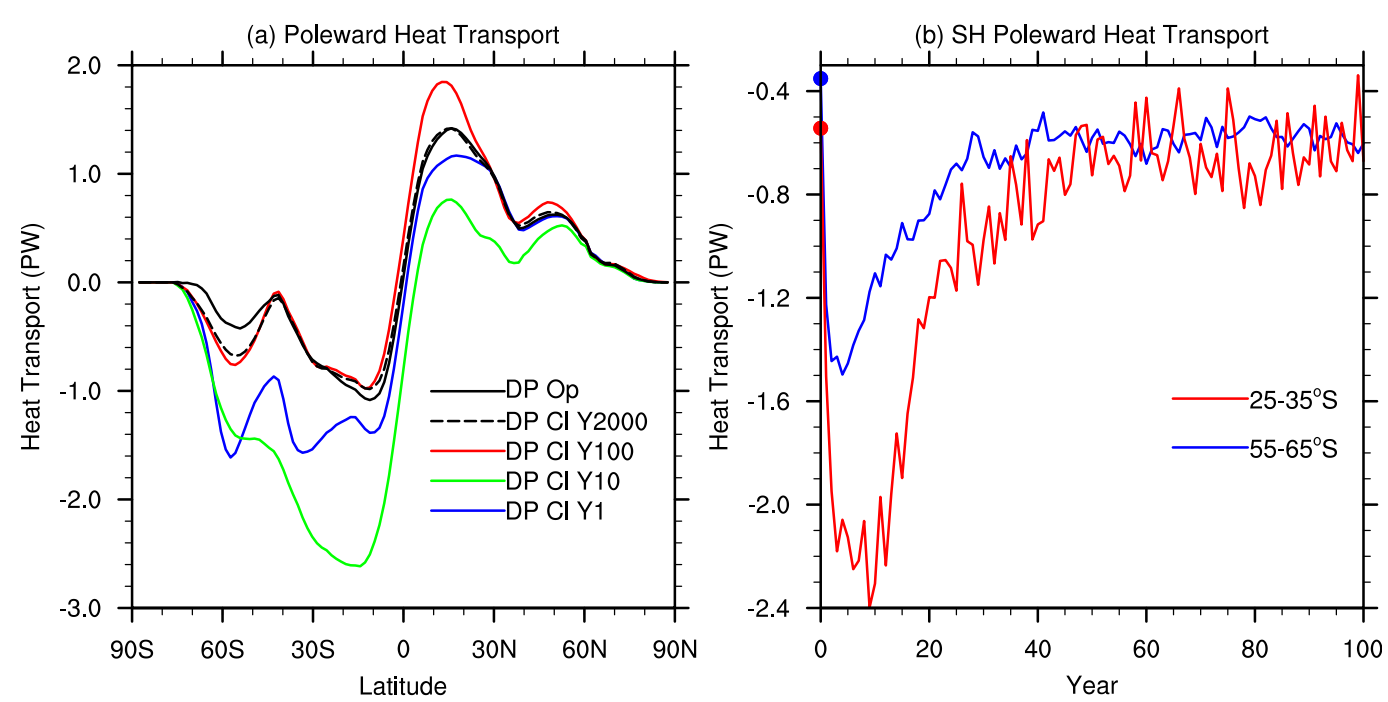

FIG. 5. (a) Poleward heat transport (PW) in $\mathrm{DP}_{\text {open }}$ (year 1500) and in $\mathrm{DP}_{\text {clsd }}$ during years 1,10 , and 100 , as well as equilibrated (year 2000). (b) Time series of poleward heat transport averaged across the latitude bands $25^{\circ}-35^{\circ}$ and $55^{\circ}-65^{\circ} \mathrm{S}$ for model years $0-100$ in $\mathrm{DP}_{\text {clsd }}$, with initial conditions highlighted $\left(\mathrm{DP}_{\mathrm{open}}\right)$. Quasi-steady states persist in PHT after year 100.

compared to $\mathrm{DP}_{\text {open }}$ (Fig. 4, top). We will see that this is linked to a near absence of Antarctic sea ice in the $\mathrm{DP}_{\text {clsd }}$ experiment, leading to a reduction in the ice albedo over the region and much warmer SST around the polar Southern Ocean in the closed DP experiment. The midlatitude jet also weakens in response to the ice-free Antarctic waters, leading to further surface warming and freshening in the ocean as both northward Ekman transport and evaporative fluxes weaken (Sen Gupta and England 2006; Thompson et al. 2011). While a warming response in Southern Ocean SST to DP closure is similar to previous ocean-only and intermediatecomplexity climate models, the mechanism obtained here is entirely different, relying on ice-albedo and wind feedback processes as will be further described below.

\section{c. Poleward heat transport}

The poleward heat transport response to closing Drake Passage closely reflects changes in the MOCnamely, a rapid invigoration of the transport of heat southward when the Antarctic overturning cell is at full strength, peaking at $2.4 \mathrm{PW}\left(1 \mathrm{PW}=10^{15} \mathrm{~W}\right)$ in the first decade, followed by a multidecadal recovery toward values more typical of the unperturbed $\mathrm{DP}_{\text {open }}$ experiment (Fig. 5). At peak change in year 4 , the heat transport across the Southern Ocean at around $60^{\circ} \mathrm{S}$ has increased more than fourfold-from $0.35\left(\mathrm{DP}_{\text {open }}\right)$ to $1.50 \mathrm{PW}\left(\mathrm{DP}_{\text {clsd }}\right)$. The southward heat transport in the subtropics is also profoundly altered by DP closure; increasing from $0.7\left(\mathrm{DP}_{\text {open }}\right)$ to $2.3 \mathrm{PW}\left(\mathrm{DP}_{\text {clsd }}\right)$ at $30^{\circ} \mathrm{S}$ by year 10 (Fig. 5a). Yet as the simulation progresses, the meridional heat transport rapidly returns toward the initial conditions of $\mathrm{DP}_{\text {open }}$.

By the time of equilibration, the PHT is almost identical between the two DP experiments at almost all latitudes (Fig. 5a), apart from changes in the latitude band of the ACC, where $\mathrm{DP}_{\text {clsd }}$ heat transport remains higher than in $\mathrm{DP}_{\text {open }}$ by around $0.25 \mathrm{PW}$. This modest increase in heat transport across the Southern Ocean in $\mathrm{DP}_{\text {clsd }}$ is consistent with warmer waters there (Fig. 4, top right), along with the suppressed ACC and the weakened atmospheric midlatitude jet (see section $3 \mathrm{e}$ ), which act in concert to enable more subtropical heat to reach the Antarctic margin via increased poleward geostrophic flow and reduced northward Ekman transport, respectively. In contrast at all other latitudes there is virtually no difference in the PHT between the two experiments. Note for example that the PHT across $40^{\circ} \mathrm{S}$ is identical between the two experiments: this means that the net ocean heat content changes south of this latitude, which are substantial in magnitude (see Fig. 4, top right), must be entirely due to differences in air-sea heat fluxes between the two experiments. We will later show that the sea ice-albedo feedbacks, not clouds, are the primary cause of this air-sea heat flux difference.

While Fig. 5 reveals the response of the total (i.e., mean plus eddy induced) poleward heat transport to DP closure, it is of interest to examine the changes in the parameterized eddy-induced PHT separately. This is revealed in Fig. S2, which shows the decomposition of the total ocean PHT into the resolved (mean) and parameterized (eddy) components for the equilibrated 
(a) Winter Sea Ice Extent

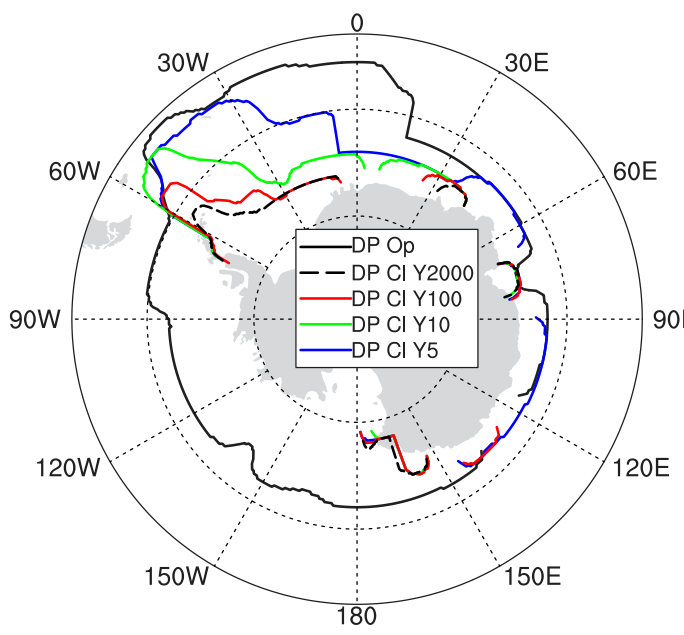

(b) Sea Ice Time Series

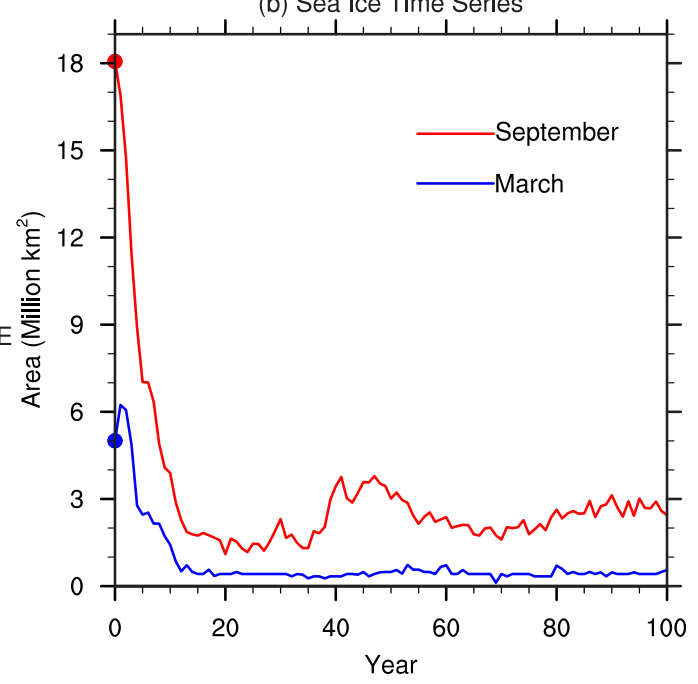

FIG. 6. (a) Wintertime Antarctic sea ice extent in $\mathrm{DP}_{\text {open }}$ (equilibrated) and in $\mathrm{DP}_{\text {clsd }}$ during years 5, 10, and 100, as well as equilibrated (year 2000). Wintertime Antarctic sea ice extent is defined as where the concentration first reaches a fraction of 0.15. (b) Time series of net March and September Antarctic sea ice extent $\left(\times 10^{6} \mathrm{~km}^{2}\right)$ during years $0-100$, defined as the total area of sea ice with concentration greater than 0.15 . Quasi-steady states persist in total sea ice extent after year 100.

states in experiments $\mathrm{DP}_{\text {open }}$ and $\mathrm{DP}_{\text {clsd. }}$. This shows that the total PHT is dominated by the non-eddy-advection fluxes except in the ACC region, but again, as would be anticipated in an ocean with no ACC, the eddy-induced component of the PHT is reduced (by around 50\%) in $\mathrm{DP}_{\text {clsd }}$ compared to $\mathrm{DP}_{\text {open }}$.

\section{d. Antarctic sea ice}

The massive initial change in poleward heat transport upon closing Drake Passage has a significant impact on the Antarctic sea ice distribution. Snapshots of the maximum Antarctic sea ice extent along with a time series of area-integrated net Antarctic sea ice volume reveal a rapid melting of Southern Hemisphere sea ice within the first decade of DP closure (Fig. 6). Unlike the meridional overturning and poleward heat transport, however, which largely recover to $\mathrm{DP}_{\text {open }}$ values within a century, the sea ice never recovers from the climatic disruption caused by DP closure. In particular, in $\mathrm{DP}_{\text {clsd }}$, Antarctic sea ice is almost entirely absent in summertime and has only very limited coverage in winter: just some $2 \times 10^{6} \mathrm{~km}^{2}$ when DP is closed compared to $18 \times 10^{6} \mathrm{~km}^{2}$ when DP is open (the Antarctic continent, for comparative purposes, is $\simeq 14 \times 10^{6} \mathrm{~km}^{2}$ in area). Thus, the wintertime sea ice extent in $\mathrm{DP}_{\text {clsd }}$ is around $30 \%$ less than the summertime sea ice extent in $\mathrm{DP}_{\text {open }}$. This remarkable difference in sea ice between the experiments has a profound impact on the ice-albedo effect around Antarctica and in turn on hemispheric and global-scale climate, as described further below.
The rapidity of sea ice decline in the coupled model in response to DP closure is easy to understand when considering that, as in observations, very little of the total Antarctic sea ice coverage in $\mathrm{DP}_{\text {open }}$ comprises multiyear ice: specifically only $3.0 \times 10^{6} \mathrm{~km}^{2}$ of the wintertime maximum of $18.0 \times 10^{6} \mathrm{~km}^{2}$ persists from one year to the next. This enables a rapid response of sea ice to the sudden warming generated by enhanced poleward heat transport when DP is closed.

\section{e. Equilibrium climate response}

Here we describe the final climatic state attained when DP is closed compared to $\mathrm{DP}_{\text {open }}$. Figure 7 shows the annual-mean surface air temperature differences between the equilibrium climates of $\mathrm{DP}_{\text {clsd }}$ and $\mathrm{DP}_{\text {open. }}$. The differences are calculated between the 10-yr averaged climate states attained at the end of the respective model experiments. Overlaid in green contours is the wintertime maximum sea ice extent in $\mathrm{DP}_{\text {clsd }}$ and $\mathrm{DP}_{\text {open }}$. In response to DP closure the Southern Hemisphere climate warms considerably, particularly in regions where considerable sea ice melt has occurred. For example, zonally averaged between $60^{\circ}$ and $70^{\circ} \mathrm{S}$, the mean surface air temperature (SAT) anomaly reaches $7.1^{\circ} \mathrm{C}$ in the annual average, as high as $9.1^{\circ} \mathrm{C}$ in the cold season (September), and $5.6^{\circ} \mathrm{C}$ in March. The higher wintertime warming is a result of the much greater differences in sea ice coverage in the cold season compared to the warm season (Figs. 6b and 7) when sea ice coverage is already low in both experiments. This occurs because of the massive seasonal retreat of 


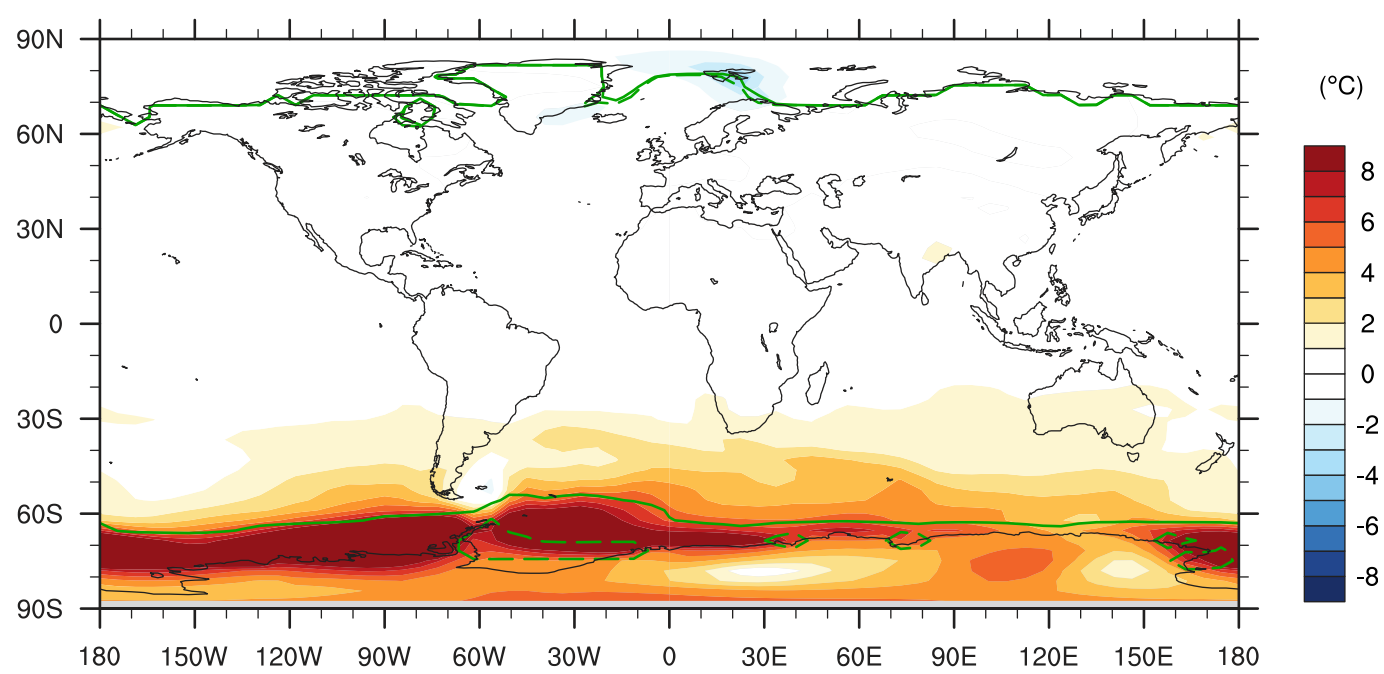

FIG. 7. Difference in annual-mean SAT $\left({ }^{\circ} \mathrm{C}\right)$ between the steady-state climates of $\left(\mathrm{DP}_{\text {clsd }}-\mathrm{DP}_{\text {open }}\right)$. Contours showing the max wintertime sea ice extent in $\mathrm{DP}_{\text {clsd }}$ (dashed) and $\mathrm{DP}_{\text {open }}$ (solid) are overlaid in green.

Antarctic sea ice during summer in the present-day climate so that both experiments have relatively limited sea ice coverage during the warm season.

Changes in oceanic sea surface temperatures (Fig. 8a) reflect the changes seen in surface air temperatures, with significant warming across much of the Southern Ocean. Surface salinity, in contrast, shows regions of both freshening and increased salinity (Fig. 8b), which reflects changes in circulation, sea ice melt, and rates of evaporation minus precipitation $(E-P)$. Overall, precipitation increases around the Antarctic coastline, apart from in the Amundsen-Bellingshausen sector (not shown), and decreases just north of this latitude band. These changes translate to nonuniform salinity differences of the same overall pattern. The barotropic streamfunction in experiment $\mathrm{DP}_{\text {clsd }}$ is overlaid for reference in Fig. 8b, revealing a marked intensification and equatorward expansion of the Weddell Gyre (54 Sv and reaching to approximately $39^{\circ} \mathrm{S}$ in $\mathrm{DP}_{\text {clsd }}$ compared to $33 \mathrm{~Sv}$ and only reaching north to $49^{\circ} \mathrm{S}$ in $\left.\mathrm{DP}_{\text {open }}\right)$. These circulation changes further decrease salinity in the South Atlantic sector as the Weddell Gyre transports fresh polar waters northward in the DP closed configuration.

Sea surface density decreases almost everywhere in the Southern Ocean in response to DP closure (Fig. 8c). This demonstrates that despite some isolated regions of increased surface salinity (Fig. 8b), warming in these regions dominates salinity changes in relation to the net surface buoyancy response to DP closure. This increase in surface buoyancy across much of the Southern Ocean explains the marked contraction in the vigorous southern sinking cell first triggered by DP closure.

Significant atmospheric circulation changes can also be seen when comparing experiment $\mathrm{DP}_{\text {clsd }}$ to $\mathrm{DP}_{\text {open }}$, particularly over the southern midlatitudes. Figure 9 shows the 925-hPa wind and atmospheric sea level pressure (SLP) differences between the experiments, revealing that the midlatitude jet is substantially weaker in experiment $\mathrm{DP}_{\text {clsd. }}$ This is related to a significant negative trend in the southern annular mode, with higher SLP over much of Antarctica and over the oceans poleward of $60^{\circ} \mathrm{S}$, and a band of decreased SLP centered near $30^{\circ} \mathrm{S}$ (Fig. 9). These SLP changes are a result of the reduced meridional temperature gradient across the latitudes of the jet, with warming strongest at high southern latitudes when DP is closed. This results in $\mathrm{a} \simeq 10 \%$ reduction in the maximum zonal-mean strength of the midlatitude westerly winds. This reduction in the peak strength of the westerlies is very similar in magnitude to that obtained by Yang et al. (2014) upon DP closure in their study. At other latitudes of the westerlies the weakening we find can be even stronger, up to $25 \%$ zonal-mean slowdown, for example, at around $53^{\circ} \mathrm{S}$. The weaker westerlies drive a reduction in equatorward Ekman transport of cold, fresh subantarctic surface waters, leading to further warming at these latitudes and, in some regions, higher salinities. The salinity field is also impacted by changes in $P-E$, runoff, sea ice melt, and geostrophic circulation now that the DP is closed; this latter effect is particularly strong in the Atlantic sector (Fig. 8b).

The $\simeq 10 \%$ weakened midlatitude jet in $\mathrm{DP}_{\text {clsd }}$ is also associated with reduced storminess and cloud cover north of around $65^{\circ} \mathrm{S}$ (Fig. 10b), resulting in slightly clearer skies, thus leading to further surface ocean warming. These cloud-cover changes are consistent with a negative shift in the southern annular mode in the $\mathrm{DP}_{\text {clsd }}$ experiment. However, the magnitude of this cloud-albedo feedback is relatively small compared to the ice-albedo feedback, with the maximum reduction in 
(a) Sea Surface Temperature

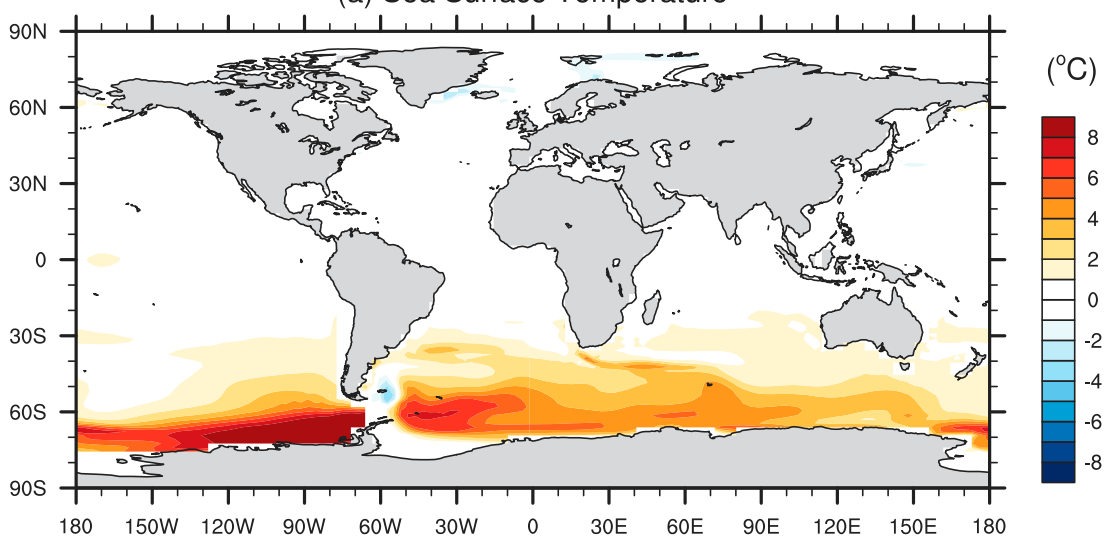

(b) Sea Surface Salinity

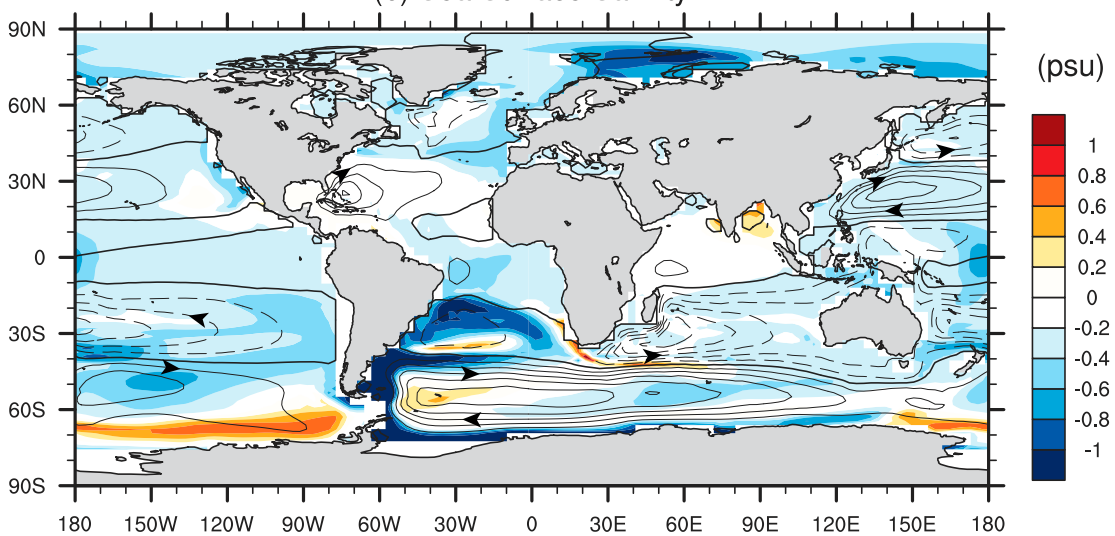

(c) Sea Surface Density

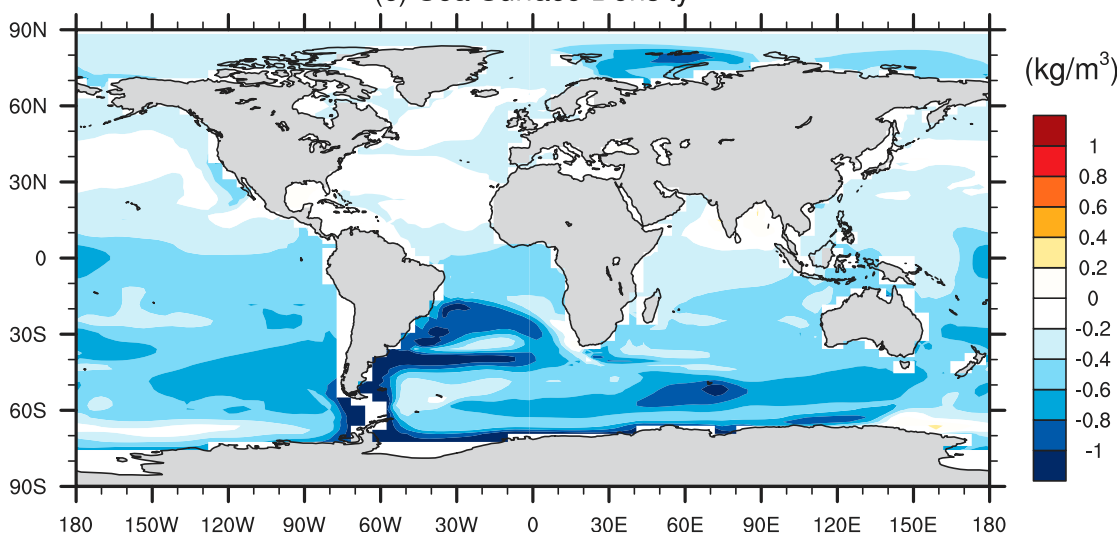

FIG. 8. Differences in annual-mean surface ocean properties between the steady-state climates of $\left(\mathrm{DP}_{\text {clsd }}-\mathrm{DP}_{\text {open }}\right)$ : (a) sea surface temperature $\left({ }^{\circ} \mathrm{C}\right)$, (b) sea surface salinity (psu), and (c) sea surface density $\left(\mathrm{kg} \mathrm{m}^{-3}\right)$. In (b), the horizontal transport streamfunction is overlaid from $\mathrm{DP}_{\text {clsd }}$ (contour interval is $10 \mathrm{~Sv}$ ), with flow direction counterclockwise for dashed contours and clockwise for solid contours.

zonal-mean total cloud fraction reaching just $3 \%-4 \%$ at $\simeq 60^{\circ} \mathrm{S}$ (figure not shown). Weaker changes are seen elsewhere, and the annual-mean cloud cover is actually higher in $\mathrm{DP}_{\text {clsd }}$ for most regions south of $65^{\circ} \mathrm{S}$, offsetting some of the warming caused by the ice-albedo effect.
This is in contrast to some previous studies that found a cloud feedback contribution to warming at these latitudes when DP is closed (e.g., Goldner et al. 2013; Yang et al. 2014); although the configuration of landmasses and gateways was different in these previous studies. 


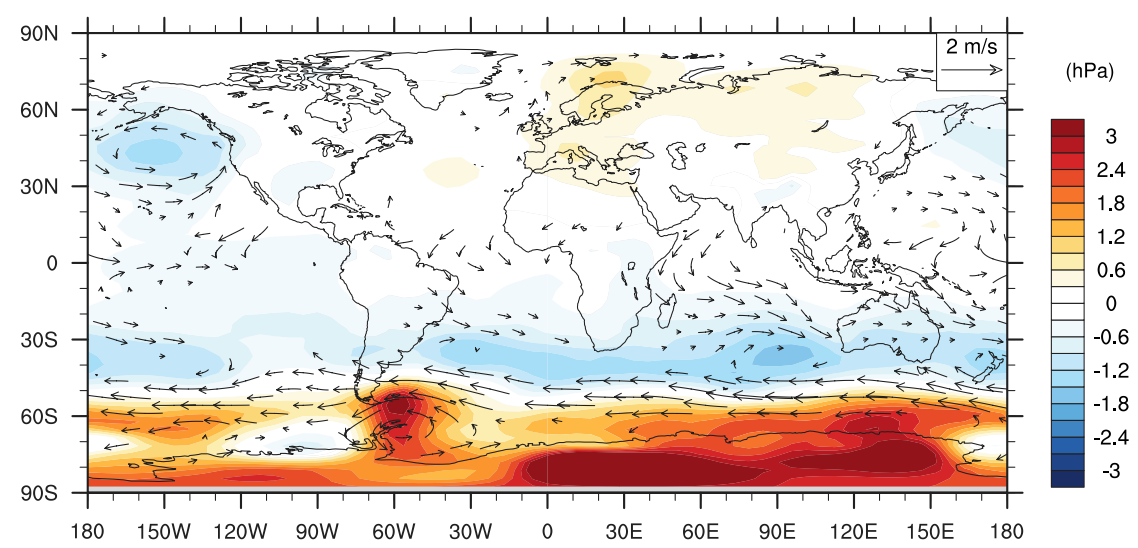

FIG. 9. Difference in sea level pressure (hPa) and $925-\mathrm{hPa}$ wind vectors between the steadystate climates of $\left(\mathrm{DP}_{\mathrm{clsd}}-\mathrm{DP}_{\mathrm{open}}\right)$. Wind vector differences of magnitude $0.2 \mathrm{~m} \mathrm{~s}^{-1}$ or less are not shown, revealing the weakening of the westerly winds over the Southern Ocean in $\mathrm{DP}_{\text {clsd. }}$.

Here, we find that the sea ice-albedo feedback dominates, accounting for most of the differences in shortwave radiation reaching Earth's surface (Fig. 10). For example, at the latitude of peak warming $\left(70^{\circ} \mathrm{S}\right)$, incoming shortwave radiation is $\simeq 50 \%$ higher in $\mathrm{DP}_{\text {clsd }}$ due entirely to sea ice-albedo changes, as cloud cover actually increases in the $\mathrm{DP}_{\text {clsd }}$ experiment at this latitude (Fig. 10b). North of $65^{\circ} \mathrm{S}$, small contributions come from atmospheric feedbacks associated with a weaker midlatitude jet, including cloud feedbacks. Taken together, both sea ice-albedo effects and, to a much lesser extent, atmospheric feedbacks due to a weaker westerly wind field lead to a substantial warming of the Southern Ocean in response to closure of the Drake Passage.

\section{Discussion and conclusions}

We have shown that the global climate response to Drake Passage closure can yield a significant Southern Hemisphere warming without requiring a corresponding invigoration of the Antarctic overturning circulation and poleward transport of heat across the DP gap. This is in marked contrast to previous studies using oceanonly and intermediate-complexity climate models. Furthermore, this heating is achieved without any change in atmospheric greenhouse gas concentrations or planetary orbital parameters. Rather, the Southern Hemisphere warming comes about owing to a melt-back in Antarctic sea ice when DP is closed and the associated reduced surface albedo over the region. In addition, a weakened midlatitude jet results from the reduced meridional temperature gradient across the Southern Ocean, which leads to further warming of subantarctic surface waters via both weakened Ekman transport and reduced cloud cover, although the ice-albedo effect dominates. These processes combine to leave annual-average Southern
Hemisphere air temperatures around $5^{\circ}-8^{\circ} \mathrm{C}$ higher around the Antarctic margin.

The importance of Antarctic sea ice extent for the global ocean meridional overturning circulation has been suggested in previous work (e.g., Marshall and Speer 2012; Ferrari et al. 2014). Marshall and Speer (2012), for example, note that the $27.6 \mathrm{~kg} \mathrm{~m}^{-3}$ neutral density surface, which roughly separates the upper and lower cells in the Southern Ocean, outcrops approximately at the position of the wintertime sea ice edge. Variations in sea ice extent will thus influence air-sea buoyancy fluxes right at the location where waters in the lower cell resurface, in turn influencing the global overturning of this water mass. Ferrari et al. (2014) extend this idea to suggest that Antarctic sea ice is fundamental in controlling not only the MOC but also the ocean's role in regulating atmospheric carbon dioxide by insulating the ocean from air-sea buoyancy and carbon fluxes. Here we have focused instead on the regulation of regional climate by Antarctica's massive expanse of sea ice, finding that gateway changes can drive dramatic surface temperature changes predominantly via the sea ice-albedo feedback. The importance of ice-albedo feedbacks around Antarctica has received much less attention than the ice-albedo effect over the Arctic, perhaps because recent sea ice melting trends have been far greater over the Northern Hemisphere. Yet Antarctic sea ice persists at much lower latitudes compared to sea ice over the Arctic, and hence we can expect the ice-albedo effect, which scales with incoming solar radiation levels, to be stronger around Antarctica unless mediated by clouds. This could have significant implications for future cryosphere changes in the region when Antarctic sea ice eventually melts.

The warming around Antarctica when DP is closed is particularly significant over the West Antarctic Ice 
(a) Net SW radiation $\mathrm{DP}_{\text {clsd }}-\mathrm{DP}_{\text {open }}\left(\mathrm{W} / \mathrm{m}^{2}\right)$

zonal mean
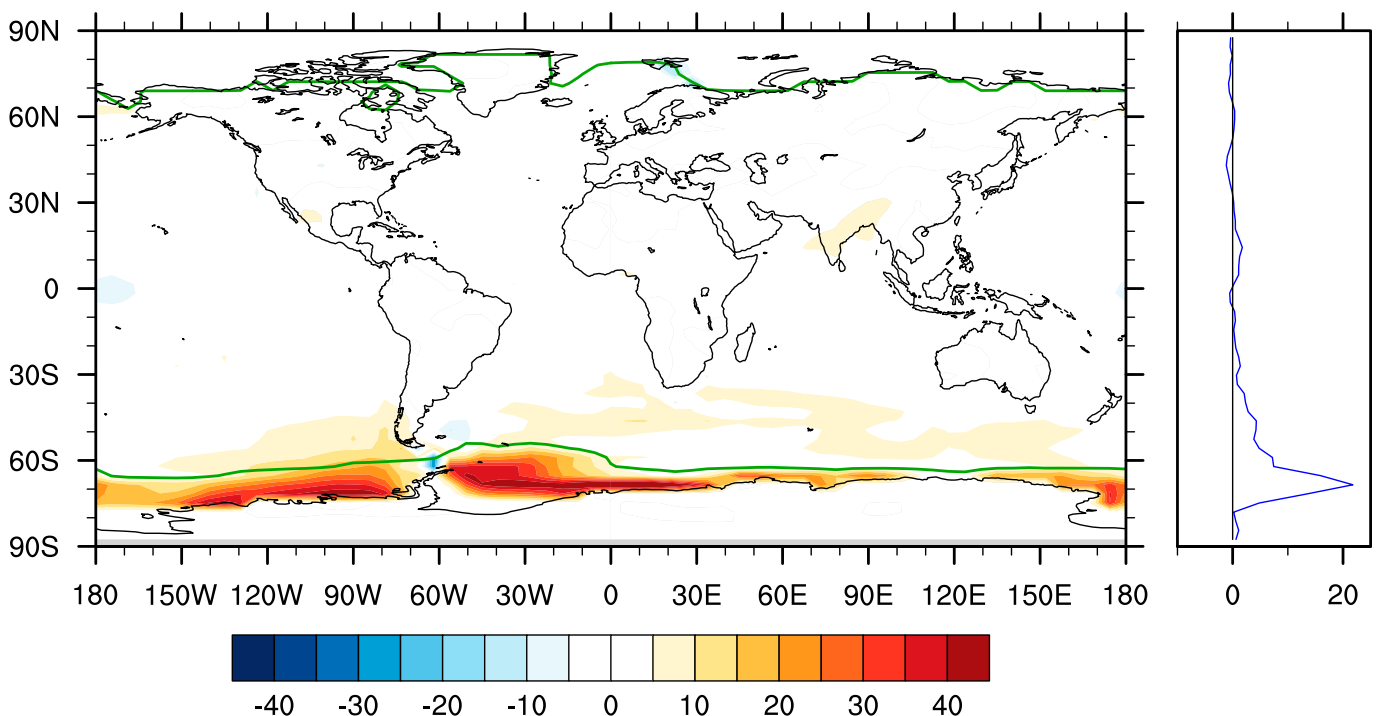

(b) Total cloud radiative effect $\mathrm{DP}_{\text {clsd }}-\mathrm{DP}_{\text {open }}\left(\mathrm{W} / \mathrm{m}^{2}\right)$

zonal mean
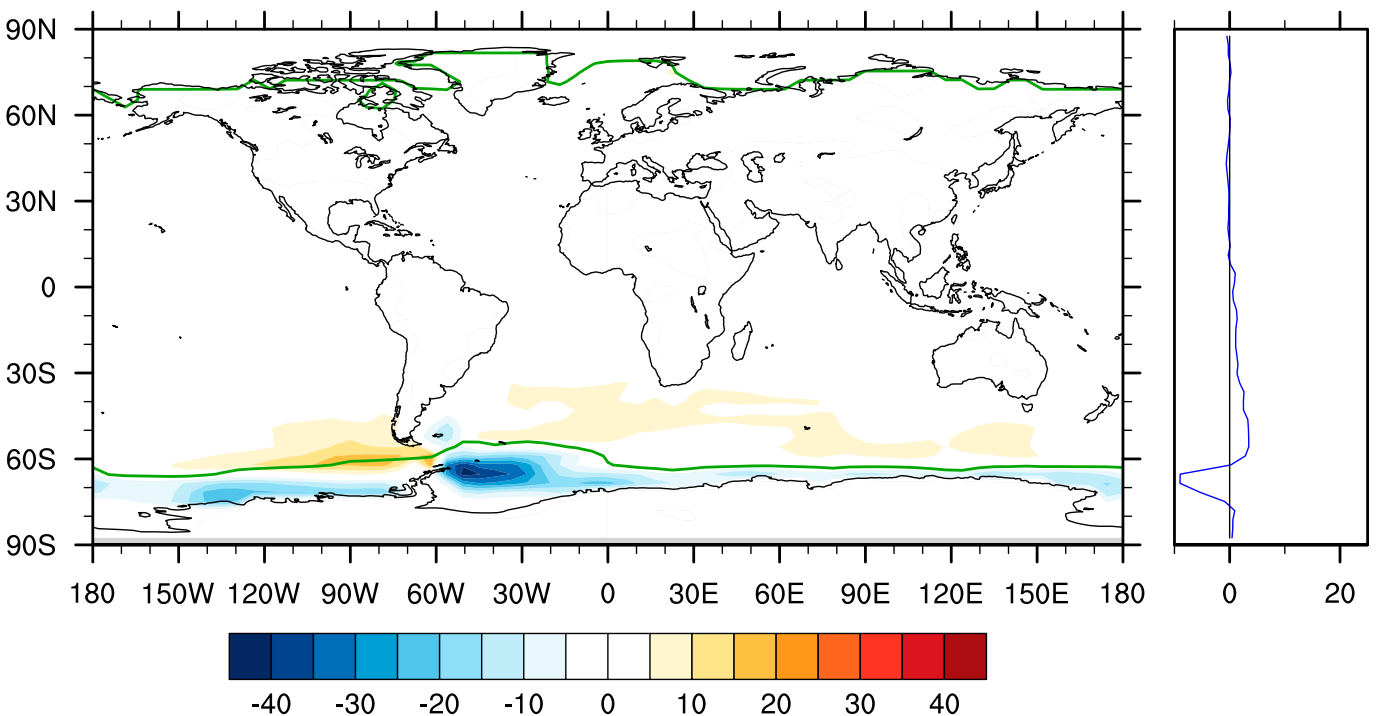

FIG. 10. (left) Differences in annual-mean atmospheric radiative properties $\left(\mathrm{W} \mathrm{m}^{-2}\right)$ between the steady-state climates of $\left(\mathrm{DP}_{\text {clsd }}-\mathrm{DP}_{\mathrm{open}}\right)$ and (right) zonal average of these differenced fields $\left(\mathrm{W} \mathrm{m}^{-2}\right)$ : (a) net shortwave radiation reaching Earth's surface and (b) total cloud radiative effect \{i.e., [total radiation at top of atmosphere (TOA)] - (clear sky radiation at TOA) $\}$. Total radiation changes at the surface in (a) are dominated by the shortwave radiation component, with net incoming minus outgoing longwave radiation changes much smaller, and mainly reflective of surface warming in $\mathrm{DP}_{\text {clsd }}$. The green overlaid contours indicate the max wintertime sea ice extent in $\mathrm{DP}_{\text {open }}$, which also denotes the regions of greatest warming around Antarctica (see, e.g., Fig. 7). These regions generally correspond with increased, not reduced, cloud cover [see (b)], demonstrating the dominant role of sea ice-albedo feedbacks there.

Sheet (WAIS) region (Fig. 7). Comparing the location of the wintertime contours of $0^{\circ} \mathrm{C}$ surface air temperature reveals a marked contraction of subfreezing air around the continent in $\mathrm{DP}_{\text {clsd }}$ (Fig. 11). While the winter season might dominate the amount of precipitation falling as snow, the long-term buildup of ice sheets requires retention of accumulated snow and ice over summer. Summertime air temperatures are thus critical for determining whether an ice cap can build up over Antarctica. Color shading in Fig. 11 reveals that over the 


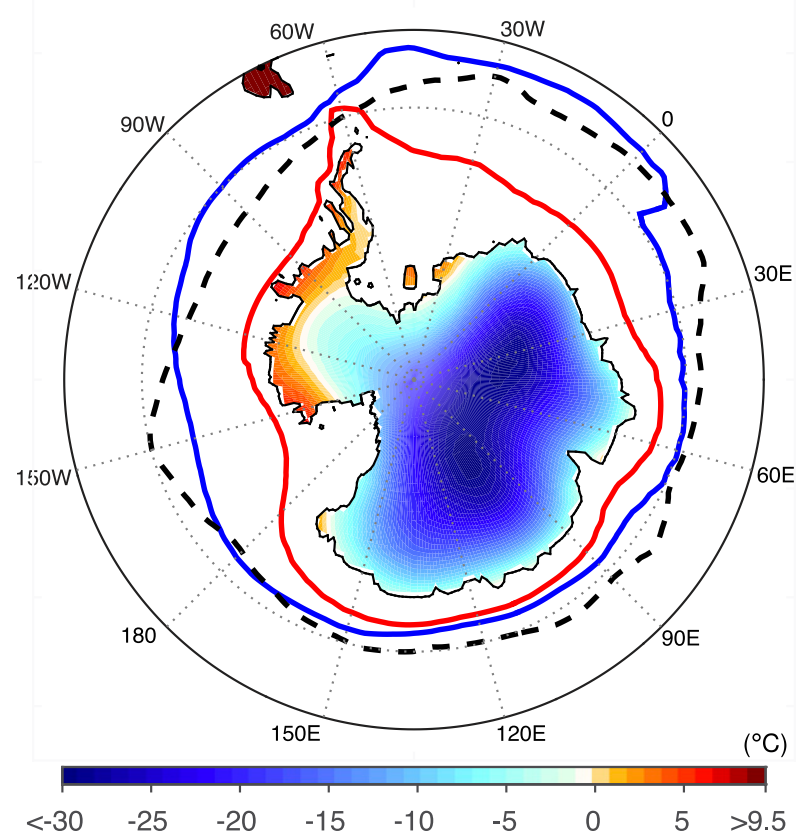

FIG. 11. Summertime (January) SAT in $\mathrm{DP}_{\text {clsd }}$ shown as color shading; temperatures above freezing point $\left(>0^{\circ} \mathrm{C}\right)$ are indicated in shades of orange and red. Overlaid is the location of the wintertime (July average) contours of $0^{\circ} \mathrm{C} \mathrm{SAT} \mathrm{in} \mathrm{DP}_{\text {clsd }}$ (red), $\mathrm{DP}_{\text {open }}$ (blue), and observed (black dashed). Observations are taken from the Twentieth Century Reanalysis, version 2, averaged over 1959-2012.

Antarctic Peninsula and WAIS regions in $\mathrm{DP}_{\text {clsd }}$, there are large areas where summertime surface air temperature is $1^{\circ}-3^{\circ} \mathrm{C}$ above freezing point, potentially too warm to retain any ice buildup over summer. In contrast in $\mathrm{DP}_{\text {open }}$ these regions remain subfreezing throughout the year. In addition, oceanic temperatures adjacent to the WAIS are substantially colder, by up to $8^{\circ} \mathrm{C}$, in $\mathrm{DP}_{\text {open }}$ compared to $\mathrm{DP}_{\text {clsd }}$ (Fig. 8a), meaning that a DP open configuration is far more likely to accommodate ice shelves and a marine-grounded ice sheet in this region compared to DP closed. The SST and SAT response to DP opening thus has potential implications for Cenozoic cooling of Antarctica and the distribution of land-ice and ice shelves during this time. In particular, opening of DP may have contributed to glacier distributions and the buildup of a marine-grounded ice sheet during the Oligocene-Eocene boundary, particularly over the Antarctic Peninsula and WAIS regions.

Before concluding this study and noting the possible implications for future Antarctic regional warming, we note here three caveats to the scope of this paper. First, the results obtained here were derived from a single model, and the findings could differ when other models with different dynamical cores are employed. However, we note that there are several aspects of consistency between our results and those of Yang et al. (2014), who use a coarse version of GFDL CM2.1. For example, both our study and Yang et al. (2014) obtain a warmer Antarctic region in response to DP closure without invoking any invigorated Southern Ocean overturning cell. In addition, both studies find a similar response in the Southern Hemisphere westerly winds. This adds confidence in the robustness of our findings. Furthermore, other studies on the global climate response to DP closure have also been derived from single model analyses (e.g., Huber et al. 2004; Zhang et al. 2010; Goldner et al. 2014) and so may suffer from model biases themselves, particularly considering that many have used a similar coupled climate model, so that independence cannot genuinely be asserted (see, e.g., Abramowitz and Gupta 2008). We thus conclude that the results obtained here, backed up by climate diagnostics and feedback mechanisms that make physical sense, most likely bear direct relevance to the observed climate system.

The second caveat is that like all past studies on this topic, the ocean model employed is too coarse to resolve mesoscale eddies over the Southern Ocean. However, as described in section 3a, the model does include the GM parameterization for subgrid-scale eddies, and this successfully captures a reduction in poleward eddy-induced heat transport when the DP is closed-something that would be expected in response to reduced baroclinic instability in the absence of an ACC. We are thus confident that our findings would be overall robust in an eddy-resolving setting.

The final caveat is regarding the context of our study, run with present-day atmospheric $\mathrm{CO}_{2}$, in regard to the paleoclimate era of the Eocene-Oligocene era. In particular, during that time atmospheric $\mathrm{CO}_{2}$ levels were much higher than today and too high to support the expansive wintertime Antarctic sea ice coverage observed in the present-day climate system (and in our $\mathrm{DP}_{\text {open }}$ experiment; see also DeConto and Pollard 2003; Huber et al. 2004; DeConto et al. 2007; Sijp et al. 2009). The ice-albedo feedback mechanism obtained here thus could not have triggered the cooling of Antarctica that occurred at the Eocene-Oligocene boundary. Instead, we propose this mechanism as a significant amplifying feedback that enhanced the initial cooling that was first triggered by a change in forcing, namely decreasing atmospheric $\mathrm{CO}_{2}$. That is, once atmospheric $\mathrm{CO}_{2}$ levels were low enough to support wintertime sea ice, the icealbedo feedback mechanism described here caused further cooling when the Southern Ocean gateway was open. Consistent with the study of DeConto et al. (2007), we find that the most significant cooling occurs around the Antarctic continental margin, not in the interior of the continent. This sea ice-albedo effect would thus impact the termination of ice sheets around 
Antarctica, more so than ice-sheet growth in the interior. In addition to regional cooling, the albedo feedback could have also reinforced Eocene-Oligocene atmospheric $\mathrm{CO}_{2}$ decreases by facilitating further oceanic $\mathrm{CO}_{2}$ drawdown via the ocean solubility pump.

In conclusion we find that the steady-state climate response to a closed Southern Ocean gateway is one characterized by large-scale and significant Antarctic regional warming, without any notable thermohaline overturning or poleward heat transport increases in the Southern Hemisphere. While this equilibrated climate response largely owes its Southern Ocean and Antarctic warmth to the ice-albedo feedback described above, as well as the associated reduced midlatitude jet, the transient adjustment upon closing DP is rather different. Closing the Drake Passage initially leads to a dramatic expansion and strengthening of the Antarctic Bottom Water cell and a rapid contraction of the North Atlantic thermohaline circulation, consistent with previous ocean-only and intermediate-complexity climate models. Then, within a decade of DP closure, the increased southward heat transport by the Antarctic cell has all but melted away Antarctic sea ice. This forces near-Antarctic $T-S$ values to both warm and freshen, becoming less dense than North Atlantic Deep Water. This leads to a collapse of the Southern Ocean cell and a return to an ocean state characterized by a confined Antarctic overturning cell and an NADW formation rate typical of the present-day climate. Poleward heat transport becomes very similar between the equilibrated DP open and DP closed cases, yet remarkably, the climate retains a strong Southern Hemisphere warming. As above, in steady state it is primarily ice-albedo and atmospheric feedbacks, not a vigorous southern sinking cell, that keep the polar oceans warm. Ultimately, DP closure can drive a hemisphere-scale warming with polar amplification, without the presence of any vigorous Southern Hemisphere overturning circulation. This suggests that the present-day glacial climate over Antarctica could be facilitated as much by the presence of sea ice around the polar continent as it is by the thermal isolation provided by the Antarctic Circumpolar Current. This could have profound ramifications for global warming; namely, if Antarctic sea ice melts significantly, ice-albedo feedbacks could drive further atmospheric warming, with peak amplitude in the vicinity of the Antarctic ice shelves and where the Antarctic ice sheets feed into the Southern Ocean.

Acknowledgments. This work was supported by the Australian Research Council (ARC), including the ARC Centre of Excellence for Climate System Science (CE110001028) and an ARC Laureate Fellowship
(FL100100214). Numerical simulations were supported by the National Computational Infrastructure (NCI) National Facility systems at the Australian National University through the National Computational Merit Allocation Scheme supported by the Australian Government.

\section{REFERENCES}

Abramowitz, G., and H. Gupta, 2008: Toward a model space and model independence metric. Geophys. Res. Lett., 35, L05705, doi:10.1029/2007GL032834.

Barker, P. F., and J. Burrell, 1977: The opening of Drake Passage. Mar. Geol., 25, 15-34, doi:10.1016/0025-3227(77)90045-7.

Cavalieri, D. J., and C. L. Parkinson, 2008: Antarctic sea ice variability and trends, 1979-2006. J. Geophys. Res., 113, C07004, doi:10.1029/2007JC004564.

Cisewski, B., V. H. Strass, and H. Prandke, 2005: Upper-ocean vertical mixing in the Antarctic Polar Front zone. Deep-Sea Res. II, 52, 1087-1108, doi:10.1016/j.dsr2.2005.01.010.

Cox, M. D., 1989: An idealized model of the World Ocean. Part I: The global-scale water masses. J. Phys. Oceanogr., 19, 1730-1752, doi:10.1175/1520-0485(1989)019<1730:AIMOTW>2.0.CO;2.

Danabasoglu, G., and J. Marshall, 2007: Effects of vertical variations of thickness diffusivity in an ocean general circulation model. Ocean Modell., 18, 122-141, doi:10.1016/ j.ocemod.2007.03.006.

DeConto, R. M., and D. Pollard, 2003: Rapid Cenozoic glaciation of Antarctica induced by declining atmospheric $\mathrm{CO}_{2}$. Nature, 421, 245-249, doi:10.1038/nature01290.

- - - and D. Harwood, 2007: Sea ice feedback and Cenozoic evolution of Antarctic climate and ice sheets. Paleoceanography, 22, PA3214, doi:10.1029/2006PA001350.

England, M. H., 1993: Representing the global-scale water masses in ocean general circulation models. J. Phys. Oceanogr., 23, 1523-1552, doi:10.1175/1520-0485(1993)023<1523: RTGSWM $>2.0 . \mathrm{CO} ; 2$.

Ferrari, R., M. F. Jansen, J. F. Adkins, A. Burke, A. L. Stewart, and A. F. Thompson, 2014: Antarctic sea ice control on ocean circulation in present and glacial climates. Proc. Natl. Acad. Sci. USA, 111, 8753-8758, doi:10.1073/pnas.1323922111.

Gent, P. R., and J. C. McWilliams, 1990: Isopycnal mixing in ocean circulation models. J. Phys. Oceanogr., 20, 150-155, doi:10.1175/ 1520-0485(1990)020<0150:IMIOCM > 2.0.CO;2.

_ J. Willebrand, T. J. McDougall, and J. C. McWilliams, 1995: Parameterizing eddy-induced tracer transports in ocean circulation models. J. Phys. Oceanogr., 25, 463-474, doi:10.1175/ 1520-0485(1995)025<0463:PEITTI > 2.0.CO;2.

Gill, A. E., and K. Bryan, 1971: Effects of geometry on the circulation of a three-dimensional Southern-Hemisphere ocean model. Deep-Sea Res., 18, 685-721.

Goldner, A., M. Huber, and R. Caballero, 2013: Does Antarctic glaciation cool the world? Climate Past, 9, 173-189, doi:10.5194/ cp-9-173-2013.

- N. Herold, and M. Huber, 2014: Antarctic glaciation caused ocean circulation changes at the Eocene-Oligocene transition. Nature, 511, 574-577, doi:10.1038/nature13597.

Gordon, H. B., and Coauthors, 2002: The CSIRO Mk3 climate system model. CSIRO Atmospheric Research Tech. Rep. 60, 130 pp.

Gregory, D., and P. R. Rowntree, 1990: A mass flux convection scheme with representation of cloud ensemble characteristics and stability-dependent closure. Mon. Wea. Rev., 118, 1483-1506, doi:10.1175/1520-0493(1990)118<1483:AMFCSW>2.0.CO;2. 
Hill, D. J., A. M. Haywood, P. J. Valdes, J. E. Francis, D. J. Lunt, B. S. Wade, and V. C. Bowman, 2013: Paleogeographic controls on the onset of the Antarctic Circumpolar Current. Geophys. Res. Lett., 40, 5199-5204, doi:10.1002/grl.50941.

Huber, M., and L. C. Sloan, 2001: Heat transport, deep waters, and thermal gradients: Coupled simulation of an Eocene greenhouse climate. Geophys. Res. Lett., 28, 3481-3484, doi:10.1029/ 2001 GL012943.

— Hemisphere and its climatic impacts in the Eocene. Palaeogeogr. Palaeoclimatol. Palaeoecol., 231, 9-28, doi:10.1016/ j.palaeo.2005.07.037.

—, H. Brinkhuis, C. E. Stickley, K. Döös, A. Sluijs, J. Warnaar, S. A. Schellenberg, and G. L. Williams, 2004: Eocene circulation of the Southern Ocean: Was Antarctica kept warm by subtropical waters? Paleoceanography, 19, PA4026, doi:10.1029/ 2004PA001014.

Hutchinson, D. K., M. H. England, A. Santoso, and A. M. Hogg, 2013: Interhemispheric asymmetry in transient global warming: The role of Drake Passage. Geophys. Res. Lett., 40, 15871593, doi:10.1002/grl.50341.

Kennett, J. P., 1977: Cenozoic evolution of Antarctic glaciation, the circum-Antarctic Ocean, and their impact on global paleoceanography. J. Geophys. Res., 82, 3843-3860, doi:10.1029/ JC082i027p03843.

Kowalczyk, E. A., J. R. Garratt, and P. B. Krummel, 1994: Implementation of a soil-canopy scheme into the CSIRO GCM-Regional aspects of the model response. CSIRO Division of Atmospheric Research Tech. Rep. 32, 59 pp.

Lefebvre, V., Y. Donnadieu, P. Sepulchre, D. Swingedouw, and Z.-S. Zhang, 2012: Deciphering the role of southern gateways and carbon dioxide on the onset of the Antarctic Circumpolar Current. Paleoceanography, 27, PA4201, doi:10.1029/ 2012PA002345.

Livermore, R., A. Nankivell, G. Eagles, and P. Morris, 2005: Paleogene opening of Drake Passage. Earth Planet. Sci. Lett., 236, 459-470, doi:10.1016/j.eps1.2005.03.027.

Marshall, J., and K. Speer, 2012: Closure of the meridional overturning circulation through Southern Ocean upwelling. Nat. Geosci., 5, 171-180, doi:10.1038/ngeo1391.

McDougall, T. J., D. R. Jackett, D. G. Wright, and R. Feistel, 2003: Accurate and computationally efficient algorithms for potential temperature and density of seawater. J. Atmos. Oceanic Technol., 20, 730-741, doi:10.1175/1520-0426(2003)20<730: AACEAF $>2.0 . C O ; 2$.

Najjar, R. G., G. T. Nong, D. Seidov, and W. H. Peterson, 2002: Modeling geographic impacts on early Eocene ocean temperature. Geophys. Res. Lett., 29, 40-44, doi:10.1029/ 2001 GL014438.

Nong, G. T., R. G. Najjar, D. Seidov, and W. H. Peterson, 2000: Simulation of ocean temperature change due to the opening of
Drake Passage. Geophys. Res. Lett., 27, 2689-2692, doi:10.1029/ 1999GL011072.

O'Farrell, S. P., 1998: Investigation of the dynamic sea ice component of a coupled atmosphere-sea ice general circulation model. J. Geophys. Res., 103, 15 751-15 782, doi:10.1029/98JC00815.

Phipps, S. J., L. D. Rotstayn, H. B. Gordon, J. L. Roberts, A. C. Hirst, and W. F. Budd, 2011: The CSIRO Mk3L climate system model version 1.0. Part 1: Description and evaluation. Geosci. Model Dev., 4, 483-509, doi:10.5194/gmd-4-483-2011.

— and the role of climate forcings over the past 1500 years. J. Climate, 26, 6915-6936, doi:10.1175/JCLI-D-12-00108.1.

Rotstayn, L. D., 2000: On the "tuning" of autoconversion parameterizations in climate models. J. Geophys. Res., 105, 15 49515 507, doi:10.1029/2000JD900129.

Santoso, A., W. Cai, M. H. England, and S. J. Phipps, 2011: The role of the Indonesian Throughflow on ENSO dynamics in a coupled climate model. J. Climate, 24, 585-601, doi:10.1175/ 2010JCLI3745.1.

_ M. H. England, and W. Cai, 2012: Impact of Indo-Pacific feedback interactions on ENSO dynamics diagnosed using ensemble climate simulations. J. Climate, 25, 7743-7763, doi:10.1175/JCLI-D-11-00287.1.

Sen Gupta, A., and M. H. England, 2006: Coupled oceanatmosphere-ice response to variations in the southern annular mode. J. Climate, 19, 4457-4486, doi:10.1175/JCLI3843.1.

Sijp, W. P., and M. H. England, 2004: Effect of the Drake Passage Throughflow on global climate. J. Phys. Oceanogr., 34, 1254-1266, doi:10.1175/1520-0485(2004)034<1254:EOTDPT>2.0.CO;2.

,$- \ldots$, and J. R. Toggweiler, 2009: Effect of ocean gateway changes under greenhouse warmth. J. Climate, 22, 6639-6652, doi:10.1175/2009JCLI3003.1.

Stickley, C. E., and Coauthors, 2004: Timing and nature of the deepening of the Tasmanian Gateway. Paleoceanography, 19, PA4027, doi:10.1029/2004PA001022.

Thompson, D. W. J., S. Solomon, P. J. Kushner, M. H. England, K. M. Grise, and D. J. Karoly, 2011: Signatures of the Antarctic ozone hole in Southern Hemisphere surface climate change. Nat. Geosci., 4, 741-749, doi:10.1038/ngeo1296.

Toggweiler, J. R., and B. Samuels, 1995: Effect of Drake Passage on the global thermohaline circulation. Deep-Sea Res. I, 42 , 477-500, doi:10.1016/0967-0637(95)00012-U.

_ J. Quat. Sci., 15, 319-328, doi:10.1002/1099-1417(200005)15:4<319:: AID-JQS545>3.0.CO;2-C

Yang, S., E. Galbraith, and J. Palter, 2014: Coupled climate impacts of the Drake Passage and the Panama Seaway. Climate Dyn., 43, 37-52, doi:10.1007/s00382-013-1809-6.

Zhang, Z.-S., Q. Yan, and H.-J. Wang, 2010: Has the Drake Passage played an essential role in the Cenozoic cooling? Atmos. Oceanic Sci. Lett., 3, 288-292, doi:10.1080/16742834.2010.11446884. 